\title{
Two novel targets of the MAP kinase Kss1 are negative regulators of invasive growth in the yeast Saccharomyces cerevisiae
}

\author{
Jeanette Gowen Cook, ${ }^{1}$ Lee Bardwell, ${ }^{1}$ Stephen J. Kron, ${ }^{2}$ and Jeremy Thorner ${ }^{1,3}$ \\ ${ }^{1}$ Department of Molecular and Cell Biology, Division of Biochemistry and Molecular Biology, University of California, \\ Berkeley, California 94720-3202 USA; ${ }^{2}$ Department of Molecular Genetics and Cell Biology, University of Chicago, \\ Chicago, Illinois 60637 USA
}

\begin{abstract}
Haploid cells of budding yeast Saccharomyces cerevisiae respond to mating pheromones by inducing genes required for conjugation, arresting cell cycle progression, and undergoing morphological changes. The same cells respond to nutrient deprivation by altering budding pattern and inducing genes required for invasive growth. Both developmental alternatives to vegetative proliferation require the MAP kinase Kss1 and the transcriptional transactivator Ste12. Using a two-hybrid screen for gene products that interact with Kss1, two homologous and previously uncharacterized loci (DIG1 and DIG2, for down-regulator of invasive growth) were identified. DIG2 is pheromone-inducible, whereas DIG1 is constitutively expressed. Dig1 colocalizes with Kss1 in the nucleus, coimmunoprecipitates with Kss1 from cell extracts in a pheromone-independent manner, and is phosphorylated by Kss 1 in immune complexes in a pheromone-stimulated manner. Kss1 binds specifically to a GST-Dig1 fusion in the absence of any other yeast protein. Using the two-hybrid method, both Dig1 and Dig2 also interact with the other MAP kinase of the pheromone response pathway, Fus3. However, neither dig1 or dig2 single mutants, nor a dig1 dig2 double mutant, have a discernible effect on mating. In contrast, dig1 dig2 cells constitutively invade agar medium, whereas a dig1 dig2 ste12 triple mutant does not, indicating that Dig1 and Dig2 share a role in negatively regulating the invasive growth pathway. High-level expression of Dig1 suppresses invasive growth and also causes cells to appear more resistant to pheromone-imposed cell cycle arrest. Ste12 also binds specifically to GST-Dig1 in the absence of any other yeast protein. Collectively, these findings indicate that Dig1, and most likely Dig2, are physiological substrates of Kss1 and suggest that they regulate Ste12 function by direct protein-protein interaction.
\end{abstract}

[Key Words: Protein kinase; two-hybrid screen; protein-protein interaction; signal transduction; gene regulation; developmental control]

Received June 5, 1996; revised version accepted September 30, 1996.

Eukaryotic cells respond to diverse extracellular signals, such as growth factors, nutrients, and environmental stresses, by altering their growth and morphology accordingly. These cues are transmitted from the cell surface through multitiered and interconnected signaling pathways to various intracellular target molecules. Haploid cells of the budding yeast Saccharomyces cerevisiae have a number of developmental options in addition to their mitotic growth and division. One such alternative developmental program is the mating process, which occurs in response to secreted peptides (mating pheromones). The multicomponent signaling cascade required

${ }^{3}$ Corresponding author. for pheromone response is perhaps the best understood signal transduction pathway known in any eukaryotic organism (Bardwell et al. 1994b), and components of this pathway are evolutionarily conserved in metazoans (Dhanasekaran et al. 1995). The mating pheromones bind to cell type-specific, $\mathrm{G}$ protein-coupled receptors. Receptor occupancy stimulates release of G $\beta \gamma$ (Whiteway et al. 1989), which is necessary to activate downstream events. One of the proposed effectors of $\beta \gamma$ is Cdc24, a guanine-nucleotide exchange factor (Zhao et al. 1995), which acts on Cdc42, a Rho-like small GTPase (Simon et al. 1995). Cdc42 is able to bind to (and presumably stimulate) Ste20 (Leberer et al. 1992), a homolog of the mammalian protein-serine kinase p $65^{\text {PAK }}$ (Manser et al. 1994; Martin et al. 1995). Ste20 activates an archetypal MAP kinase (MAPK) cascade (Cairnes et 
al. 1992; Errede et al. 1993; Neiman and Herskowitz 1994), consisting of Stell (a MEK kinase), Ste7 (a MEK), and two MAPKs, Kss1 and Fus3, that are partially redundant in function (Elion et al. 1991; Ma et al. 1995). Hence, Ste20 functions as a MEK kinase kinase (Wu et al. 1995/. Each of the four different classes of protein kinase in this MAPK cascade has been shown to associate with the Ste5 protein, which appears to serve, at least in part, as a platform or scaffold for these other signaling components (Choi et al. 1994; Marcus et al. 1994; Printen and Sprague 1994; Leeuw et al. 1995). Both Kss1 and Fus3 efficiently phosphorylate Ste7 (Bardwell et al. 1996; Errede and Ge 1996), presumably as part of a feedback mechanism for modulating the activity of this enzyme. Likewise, Fus3 has been shown to phosphorylate Ste5 (Kranz et al. 1994). However, only two downstream substrates of Kss1 and Fus3 have been identified previously. These targets are the Cdk inhibitor Farl (Chang and Herskowitz 1990, 1992), which is phosphorylated most efficiently by Fus3 (Elion et al. 1993; Peter et al. 1993; Tyers and Futcher 1993) and the Ste 12 transcription factor (Elion et al. 1993; L. Bardwell, J.G. Cook, and J. Thorner, unpubl.). As a result of these modifications (and presumably others) cell cycle progression is arrested in the $G_{1}$ phase, the expression of multiple genes is induced, and dramatic changes occur in cell polarity and morphology in preparation for cytoplasmic and nuclear fusion (for review, see Sprague and Thorner 1992; Kurjan 1993).

As a developmental response to changes in nutrient conditions, $S$. cerevisiae cells can undergo a dimorphic transition (for review, see Kron and Gow 1995). Under conditions of nutrient deprivation, especially nitrogen limitation, MATa/MAT $\alpha$ cells convert from their unicellular, ovoid yeast form to a more elongated, filamentlike pseudohyphal form (Gimeno et al. 1992; Blacketer et al. 1993). This reversible differentiation process is characterized by the formation of elongated cells that bud synchronously in a unipolar fashion and are capable of invading solid agar medium (Kron et al. 1994). In contrast, haploid cells form only short filaments and display invasive growth only on rich agar medium (Roberts and Fink 1994). Furthermore, only a subset of laboratory strains of $S$. cerevisiae, specifically those derived from the Belgian $\Sigma 1278$ lineage (Wiame et al. 1985), are capable of displaying such changes in response to nutrient deprivation. In this strain background, it has been shown that various components of the same MAPK pathway that is required for mating are also necessary to manifest filamentous and invasive growth. Ste20, Ste11, Ste7, and Ste12 are all required for both the diploid and haploid versions of pseudohyphal and invasive growth (Liu et al. 1993; Roberts and Fink 1994). Kssl appears to have a supportive rather than essential role in pseudohyphal growth in diploids, and Fus3 is totally dispensible for this process (Liu et al. 1993). In marked contrast, in haploid cells Kss1 is required for invasive growth, whereas Fus3 negatively regulates this process (Roberts and Fink 1994). Thus, rather than serving essentially redundant roles as they do in the pheromone response pathway,
Kss1 and Fus3 have opposite functions in the signaling pathway that leads to invasive growth by haploid cells.

Given that Kss1 and Fus3 are responsible for transmitting two different kinds of signals, each of which elicits a multiplicity of cellular responses, it seemed reasonable to conclude that these MAPKs should have multiple target substrates, as well as multiple regulatory and accessory factors. As one approach for identifying novel proteins that interact with Kss1, we used the two-hybrid screen (Fields and Song 1989; Bartel and Fields 1995). Here, we describe the isolation and characterization of two novel genes, DIG1 and DIG2, which encode proteins that occupy the same cellular compartment as Kssl, associate with Kss1, and are substrates of Kssl in vitro. We further demonstrate using genetic analysis that Dig1 and Dig2 are negative regulators of invasive growth by showing that loss of Dig1 and Dig2 permits invasive growth by haploid strains that are normally incapable of undergoing this developmental switch. Moreover, we found that Digl can associate with Ste 12 in the absence of any other yeast protein, suggesting that Dig1 (and presumably Dig2) negatively regulates the Ste12-dependent expression of genes required for invasive growth by direct association with Ste12.

\section{Results}

Identification of gene products that interact with Kss1

To perform a two-hybrid screen to identify novel proteins that interact with Kssl, we initially fused two different DNA-binding domains to the amino terminus of Kssl. Both Gal4 DNA-binding domain (GDB)-Kssl and LexA DNA-binding domain-Kssl chimeras were constructed. Although both fusion proteins were expressed at a readily detectable level, neither was able to complement the mating defect of a MATa kss $1 \Delta$ fus $3 \Delta$ double mutant (data not shown). In addition, neither fusion protein, when expressed at a high level, was able to cause the formation of a turbid halo in the standard agar diffusion bioassay for pheromone-induced $G_{1}$ arrest (Julius et al. 1983), despite the fact that even many catalytically inactive mutants of Kssl are able to do so (Ma et al. 1995). Moreover, neither fusion, when coexpressed with a construct (generously provided by S. Fields, University of Washington, Seattle, WA) in which full-length Ste12 (a known Kss1 target) was fused to the carboxyl terminus of the sequence encoding the Gal4 transcriptional activation domain $|\mathrm{GAD}|$, was able to generate a reproducibly positive signal indicative of an authentic interaction (data not shown). These results suggested that the structure and/or function of Kss1 is highly sensitive to alterations at its amino terminus.

To avoid this problem, a third fusion was prepared in which the GDB was fused to the carboxy-terminal end of full-length Kssl. Immunoblot analysis using a rabbit polyclonal anti-Kss 1 antiserum (Ma et al. 1995) detected a protein species that migrated at the molecular weight expected for this fusion protein (data not shown). This 
Table 1. S. cerevisiae strains

\begin{tabular}{|c|c|c|}
\hline Strain & Genotype & Source \\
\hline YPH499 & 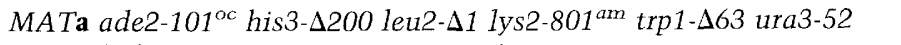 & Sikorski and Hieter (1989) \\
\hline YPH500 & $M A T \alpha$ (otherwise isogenic to YPH499) & Sikorski and Hieter (1989) \\
\hline YPH501 & MATa/MAT $\alpha(\mathrm{YPH} 499 \times \mathrm{YPH} 500)$ & Sikorski and Hieter (1989) \\
\hline Y190 & $\begin{array}{l}\text { MATa ade2-101 }{ }^{\circ C} \text { cyh2 gal4 gal80 his3 leu2-3, } 112 \text { trp1-901 ura3-52 } \\
\text { URA3::GAL1-1acZ LYS2::GAL1-HIS3 }\end{array}$ & $\begin{array}{l}\text { S. Elledge (Baylor University, } \\
\text { Houston, TX) }\end{array}$ \\
\hline DK $499^{a}$ & YPH499 sst1- $\Delta 5::$ his $G$ & D. Kaim \\
\hline YDM $210^{\mathrm{b}}$ & YPH499 fus3-6::LEU2 sst2A::ura3 & D. $\mathrm{Ma}$ \\
\hline YDM230 & YPH499 kss1 $1::$ hisG fus3-6::LEU2 & Ma et al. (1995) \\
\hline $\mathrm{YDM}^{2} 00^{\mathrm{c}}$ & YPH499 sst2A::ura3 & Ma et al. (1995) \\
\hline YDM420d & YPH499 kss14::hisG sst2::ura3 & D. $\mathrm{Ma}$ \\
\hline JCY3 & YPH499 dig1- $\Delta 1:: H I S 3$ & This work \\
\hline JCY4 & YPH499 dig2- $\Delta 1:: T R P 1$ & This work \\
\hline JCY5 & YPH499 dig1- $\Delta 1:: H I S 3$ dig2- $\Delta 1:: T R P 1$ & This work \\
\hline $\mathrm{JCY}^{\mathrm{e}}$ & $M A T \alpha$ otherwise isogenic to JCY5 & This work \\
\hline $\mathrm{YD}^{\mathrm{f}}$ & MATa/MATa dig1/dig1 dig2/dig2 (JCY5 X JCY6) & This work \\
\hline JCY512 & YPH499 dig1- $\Delta 1:: H I S 3$ dig2- $\Delta 1:: T R P 1$ ste $12::$ LEU2 & This work \\
\hline $\mathrm{JDY}^{\mathrm{g}}$ & YPH499 ste12::LEU2 & J.L. Davis \\
\hline $10560-4 \mathrm{~A}$ & MATa his3::hisG leu2::hisG trp1::hisG ura3-52 & $\begin{array}{l}\text { G.R. Fink (MIT, Cambridge, } \\
\text { MA) }\end{array}$ \\
\hline$\sum 1278 b$ & MATa/MATo ura3-52/ura3-52 leu2::hisG/leu2::hisG & Liu et al. (1993) \\
\hline BJ2168 & MATa gal2 leu2 pep4-3 prb1-1112 prc1-407 trp1 ura3-52 & Jones (1991) \\
\hline $\mathrm{DCl} 4$ & MATa his1 & $\begin{array}{l}\text { J.B. Hicks (Cold Spring Harbor } \\
\text { Laboratory, Cold Spring } \\
\text { Harbor, NY) }\end{array}$ \\
\hline DC17 & MATa his1 & J.B. Hicks \\
\hline
\end{tabular}

a Strain YPH499 was transformed by D. Kaim (this laboratory) with a DNA fragment containing the sst1- $55::$ his $G::$ URA3::hisG allele from plasmid pJGsst1, which has been described in detail elsewhere (Reneke et al. 1988), selecting for Ura ${ }^{+}$transformants and testing for acquisition of super-sensitivity to pheromone-induced growth arrest (Chan et al. 1983), and subsequently selecting for a ura $3^{-}$ derivative using medium containing 5-fluoro-orotic acid (5-FOA) (Boeke et al. 1984).

${ }^{\mathrm{b}}$ Strain YDM210 was constructed in two steps by D. Ma (this laboratory). YPH499 was transformed with an NheI-HindIII fragment containing the fus3-6::LEU2 allele from plasmid pYEE98 (Elion et al. 1990), and disruption of the chromosomal FUS3 gene was confirmed by Southern hybridization, yielding YDM200 (YPH499 fus3-6::LEU2). To generate YDM210, the sst2 $::$ ura3 allele present in plasmid pBC14 was introduced into YDM200 by the two-step gene transplacement method of Scherer and Davis (1979), as described previously (Ma et al. 1995), and confirmed by Southern hybridization and by acquisition of pheromone hypersensitivity.

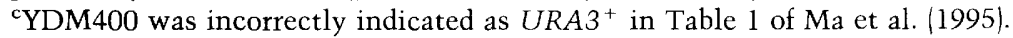

${ }^{\mathrm{d}}$ Strain YDM420 was constructed in two steps by D. Ma (this laboratory). YPH499 was transformed with the kss $1 \Delta::$ his G::URA3::hisG allele (Ma et al. 1995), and disruption of the chromosomal KSS1 locus was confirmed by Southern hybridization. A Ura ${ }^{-}$derivative was selected on 5-FOA medium, yielding YDM600 (YPH499 kss1::hisG). To generate YDM420, the sst2 $\Delta:$ ura3 allele was introduced into YDM600, as described in footnote $b$.

eJCY5 was transformed with a multicopy plasmid expressing the HO gene (Herskowitz and Jensen 1991) from the GAL1 promoter, progagated briefly on galactose, plated on medium containing glucose and 5-FOA, and screened for colonies that mated reproducibly as MAT $\alpha$, one of which was designated JCY6.

${ }^{\mathrm{f}}$ To generate a homozygous dig1/dig1 dig2/dig2 MATa/MAT $\alpha$ diploid, individual cells of JCY5 and JCY6 were juxtaposed by micromanipulation and the resulting diploid clones were confirmed by their lack of mating phenotype.

gStrain JCY5 was transformed with a BamHI fragment from plasmid pLB1367 /gift of G. Ammerer, Research Institute of Molecular Pathology, Vienna, Austria), in which an internal $1.1-\mathrm{kb}$ XbaI fragment of STE12 is replaced with the LEU2 gene, and Leu ${ }^{+}$transformants were scored for sterility that could be complemented by a plasmid (YEp352GAL-STE12) expressing STE12 at its uninduced level on raffinose-containing medium (gift of S. Fields, University of Washington, Seattle, WA). Strain JDY3 was constructed in the same manner by J.L. Davis (this laboratory) by transformation of YPH499.

Kss 1-GBD chimera was able to complement weakly the mating defect of MATa kss $1 \Delta$ fus $3 \Delta$ tester strain and was able, when overproduced, to cause a turbid halo in the plate assay for pheromone response (data not shown). Most significantly, the Kss1-GDB fusion also consistently scored positive for interaction with the tester GAD-Ste12 chimera (data not shown) and with various other GAD-Ste12 fusions in the two-hybrid test /see Fig. 1). Because the Kss1-GDB carboxy-terminal fusion behaved more like native Kssl than either of the amino- terminal fusions, it was used to conduct a two-hybrid screen for interacting gene products.

For this purpose, strain Y190 (Table 1), which contains two GAL promoter-driven reporter genes /yeast HIS 3 and Escherichia coli lacZ), was cotransformed with a plasmid encoding the Kss1-GDB fusion and either a library of yeast cDNAs fused to the GAD coding sequence or a library of random yeast genomic DNA fragments fused to the same sequence. Positive clones were initially selected via their robust level of HIS 3 expression, as judged 


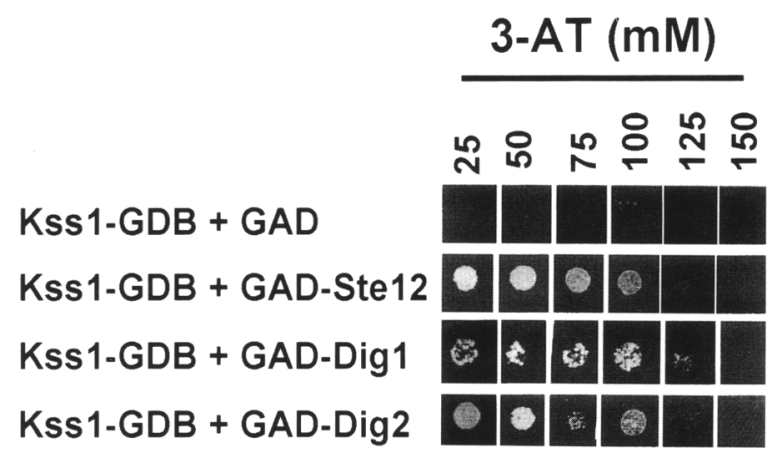

Figure 1. A two-hybrid screen for proteins that interact with Kssl identifies two novel genes, DIG1 and DIG2. Serial 10-fold dilutions (left to right) of exponentially grown cultures $\left(\sim 10^{7}\right)$ ml) of strain Y190 cotransformed with a plasmid (pIGC2) expressing a Kss 1-GBD chimera and a plasmid expressing either GAD alone (top row), a GAD-Stel2 fusion (second row), a GAD-Dig1 fusion (third row), or a GAD-Dig2 fusion (bottom row|, obtained from library screening, were spotted onto plates containing SCGlc-Trp-Leu-His medium and the various concentrations of 3-AT indicated. Because 3-AT is a competitive inhibitor of the His3 enzyme, the level of 3-AT resitance is an indicator of the magnitiude of chromosomal GAL $L_{U A S}:$ HIS3 reporter expression and, thus, of the strength of the interaction between Kssl-GDB and the GAD-containing fusion protein.

by their ability to grow on agar medium containing 50 mM 3-amino-1 $H$-1,2,4-triazole (3-AT), a competitive inhibitor of the His3 enzyme (Klopotowski and Wiater 1965 |, and then subjected to a secondary screen for vigorous production of $\beta$-galactosidase, as judged by the generation of blue color in permeabilized colony replicas using the standard 5-bromo-4-chloro-3-indolyl- $\beta$-D-galactoside (X-Gal) indicator dye (Miller 1972). Library plasmids from the reproducibly positive isolates were recovered and characterized using conventional recombinant DNA methods and direct nucleotide sequence analysis (Sambrook et al. 1989).

In the collection of plasmids obtained in this fashion from $\sim 6 \times 10^{6}$ transformants screened, a total of 11 encoded GAD-Ste12 fusions, representing seven distinct isolates. The recovery of Ste12-containing fusions from a random screen further validated the conclusion that the Kss1-GDB chimera was able to interact with an authentic Kssl substrate. This result also suggested that the fusion would also be capable of identifying other proteins that associate with Kss1 in a bona fide manner. Indeed, in this same screen (Fig. 1), we obtained seven independent isolates that encoded different, but overlapping, segments of the same novel gene, which we designated DIG1, as well as four independent isolates of a second, homologous gene, which we termed DIG2, based on the phenotypes of null alleles in these genes (see below). Our analysis of the complete DNA sequences of DIG1 and DIG2 confirmed the open reading frames for these coding sequences (GenBank accession nos. U44030 and U33050, respectively), which were obtained as the result of the recently completed international effort to determine the nucleotide sequence of the entire $S$. cerevisiae genome. None of the GAD-Dig1 and GAD-Dig2 fusions was able to yield a positive two-hybrid interaction when coexpressed with several other DNA-binding chimeras, including GDB fusions to a mammalian protein kinase (Raf), a mammalian protein kinase substrate $(\mathrm{Rb})$, and two different nuclearly localized yeast proteins (Fpr3 and Rad3) (data not shown). These results demonstrated that the interaction of GAD-Digl and GADDig2 with Kss1-GDB was specific.

As judged by the level of resistance to 3-AT or the degree of blue color on X-Gal filter replicas, the strength of the association between the GAD-Dig1 and GADDig2 fusions and the Kss1-GDB chimera was not altered detectably by treatment of the Y190 cells /which are $M A T a)$ with $\alpha$-factor mating pheromone (data not shown). Likewise, the signal observed was not appreciably different when GAD-Dig1 or GAD-Dig2 were coexpressed with a catalytically inactive Kss 1 (K42R)-GDB derivative. Thus, the interaction of GAD-Digl and GAD-Dig2 with Kss1-GDB appeared to be largely constitutive and was neither dependent on, nor attenuated by, the protein kinase activity of Kss1. As judged by the two-hybrid method, both the GAD-Dig1 and GAD-Dig2 fusions were able to interact with a GDB-Fus3 fusion (Printen and Sprague 1994) (data not shown).

\section{Sequence and expression of the DIG1 and DIG2 genes}

DIG1 resides on the left arm of chromosome 16, adjacent to MNN9 and DIG2 is located on the right arm of chromosome 4, adjacent to PHO8. An alignment of the deduced amino acid sequences of the 452-residue Digl (calculated molecular weight of 49,360 ) and the 323 -residue Dig2 (calculated molecular weight of 36,883 ) polypeptides showed that they are homologous (Fig. 2). The two proteins share $27 \%$ amino acid sequence identity and $42 \%$ similarity, if standard conservative amino acid substitutions are considered. Both the proteins are highly charged, rich in proline, and contain multiple occurrences of serine-proline and threonine-proline, which are the minimal consensus sites for phosphorylation by the proline-directed MAPKs (Alvarez et al. 1991; ClarkLewis et al. 1991; Davis 1993). The smallest segment of either protein that was recovered as an isolate in the two-hybrid screen was the carboxy-terminal half of Digl (residues 213-452). The two proteins share a reasonable degree of similarity over this region (aside from insertions in the significantly longer Dig1 protein), and the majority of the serine-proline and threonine-proline sites (four of six in Dig1 and three of five in Dig2) fall in this same segment of each protein. These considerations suggest that the carboxy-terminal portions of Digl and Dig2 are sufficient for their interaction with Kss1. Other than their homology to each other, Dig1 and Dig2 bear no extensive resemblance to any other proteins in currently available data bases.

Expression of DIG1 and DIG2 was examined by RNA hybridization analysis in two different laboratory strain backgrounds: an isogenic set of S288C-derived MATa 


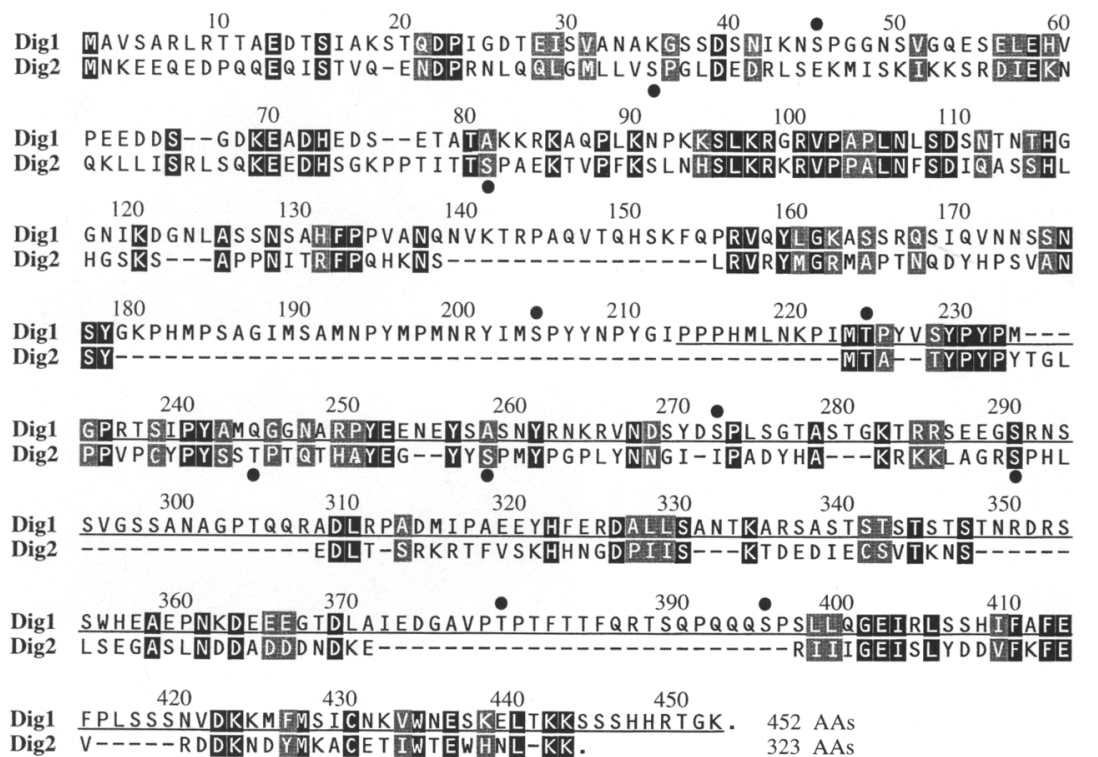

Figure 2. Dig1 and Dig2 are homologous proteins. The deduced amino acid sequences of the $D I G 1$ and DIG2 gene products were aligned using the FAST-P algorithm (Lipman and Pearson 1985), and then optimized by eye. Identical residues are given as white-on-black letters; conventional conservative amino acid substitutions $(\mathrm{D}, \mathrm{E} ; \mathrm{K}, \mathrm{R}, \mathrm{H} ; \mathrm{F}, \mathrm{Y}, \mathrm{W} ; \mathrm{Q}, \mathrm{N}$; $\mathrm{S}, \mathrm{T} ; \mathrm{L}, \mathrm{V}, \mathrm{I}, \mathrm{M}$; $\left.P, G_{1}, A ; D, N ; E, Q ; A, S, C\right)$ are shaded. Dashes indicate single-residue gaps inserted to optimize the alignment. The smallest segment of Dig1 isolated as a GAD fusion in the two-hybrid screen is underlined. Potential MAP kinase phosphorylation sites (Ser-Pro or Thr-Pro) are indicated by the solid circles above (for Digl) and below (for Dig2) each line.

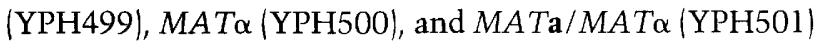
strains; and a MATa haploid and MATa/MAT $\alpha$ diploid of the $\Sigma 1278$ lineage. The $\sim 1.9-\mathrm{kb}$ DIG1 mRNA was readily detectable and, like KSS1 (Courchesne et al. 19891, was expressed at approximately the same level in all three cell types and unaffected by $\alpha$-factor treatment of MATa cells (Fig 3A). In contrast, basal expression of the $\sim 1.4-\mathrm{kb}$ DIG2 transcript was barely detectable in all three cell types, but was markedly elevated (at least threefold) in MATa cells treated with $\alpha$-factor (Fig. 3B). Not unexpectedly, the sequence of the 5 '-flanking region of the DIG2 coding sequence contains one perfect and one seven out-of-eight match to the consensus pheromone response element (Ste12-binding site)/Van Arsdell and Thorner 1987; Dolan et al. 1989). The apparent sizes of both mRNAs are more than sufficient to encode the DIG1 and DIG2 open reading frames.

Dig1 is a nuclear protein

We have shown previously that the bulk of the cellular pool of Kssl is found in the nucleus (Ma et al. 1995). If Dig1 and Dig2 interact with Kss1 in vivo, then these proteins should occupy the same subcellular compartment as Kss1. Both Dig1 and Dig2 contain extended
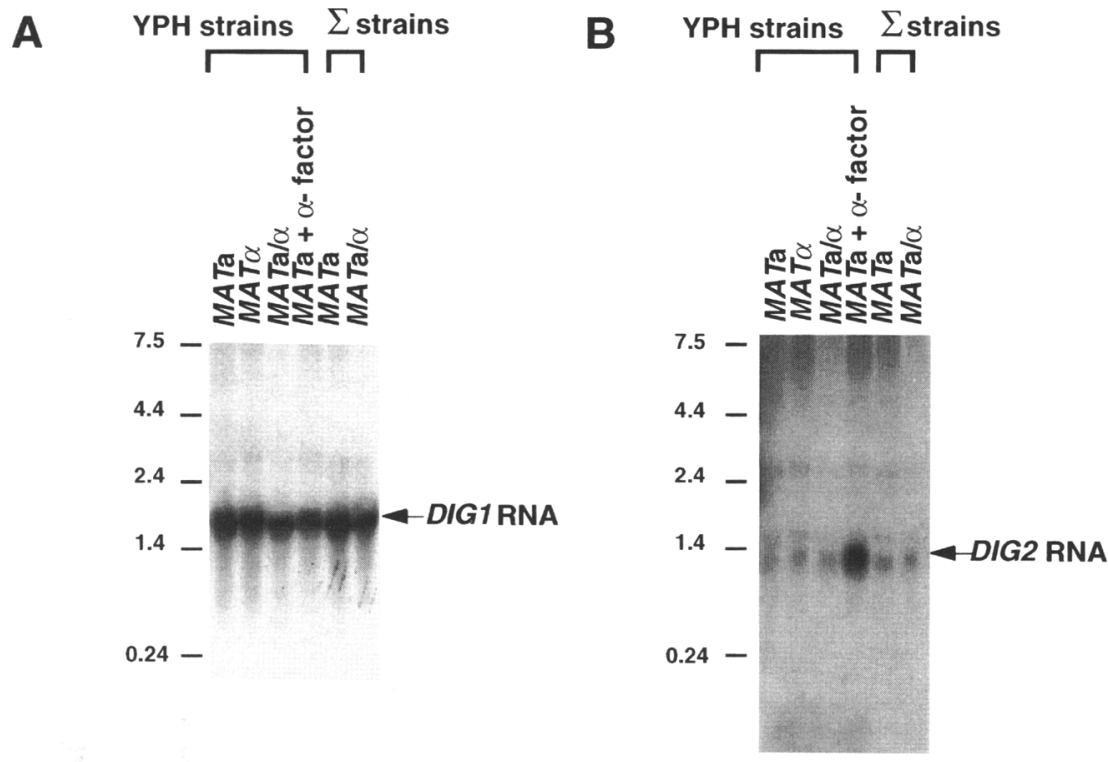

Figure 3. Expression of DIG1 and DIG2. Total RNA $(50 \mu \mathrm{g})$ from the strains indicated (see also Table 1), grown and treated with pheromone as described in Materials and Methods, was extracted, resolved by agarose gel electrophoresis, blotted to a nylon membrane, and probed with ${ }^{32} \mathrm{P}-\mathrm{la}$ beled internal fragments of either DIG1 -CMD1RNA (A),DIG2 (B), or CMD1 (insert). 
blocks of basic amino acids (residues 83-102 and 88-105, respectively) in a context very similar to that present in the nuclear localization signals found in other yeast nuclear proteins (Osborne and Silver 1993). To address the localization of Dig1, a rabbit polyclonal anti-Digl antiserum was raised against a bacterially expressed GST-Dig1 fusion protein, as described in Materials and Methods. This antiserum recognized a doublet of bands with a mobility on SDS-PAGE corresponding to an apparent molecular mass of $\sim 62 \mathrm{kD}$ (Fig. 4). This doublet represents the DIG1 gene product because these bands were absent in two independently derived dig1s strains and were greatly elevated (along with a series of degradation products) when Digl was overexpressed from the GAL1 promoter (Fig. 4). The apparent size of Dig1 based on gel mobility is significantly larger than its calculated molecular weight, which is a frequently observed anomaly for highly charged and proline-rich proteins (for example, see Benton et al. 1994). Neither the steady-state level nor the electrophoretic mobility of Dig1 were detectably altered by prior pheromone treatment of the cells (data not shown).

To determine the subcellular distribution of Digl, we used indirect immunofluorescence (Fig. 5). When DIG1+ cells were fixed and stained, bright fluorescence was seen that was congruent with that observed for the DNA dye, 4',6-diamidino-2-phenylindole (DAPI), indicating that Dig1 is located predominantly in the nucleus. Even when Dig1 was markedly overexpressed from the GAL1 promoter, the signal (now much brighter) was still confined to the nucleus. Faint fluorescence observed outside the nucleus was strictly a result of nonspecific staining

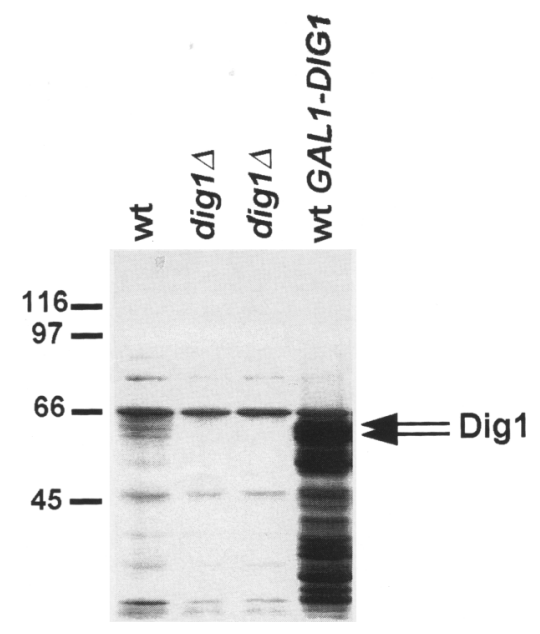

Figure 4. Specificity of the anti-Digl antiserum. Samples of extracts $(50 \mu \mathrm{g}$ total protein), prepared from YPH499 (wt), two independently generated isolates of JCY3 (dig1 14$)$, and YPH499 transformed with $\mathrm{p} G A L 1-D I G 1$ (right lane), grown in SC medium containing $2 \%$ galactose and $0.2 \%$ sucrose land, where necessary, lacking uracil to maintain selection for the plasmid), were resolved on a $10 \%$ SDS-polyacrylamide gel, transferred to nitrocellulose, and analyzed by immunoblotting with rabbit polyclonal anti-Digl antibodies as described in Materials and Methods.
A

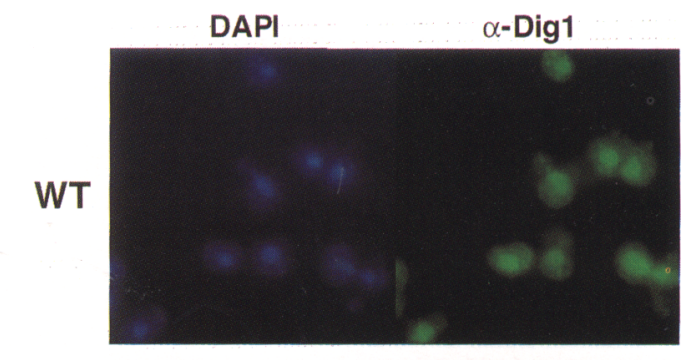

B

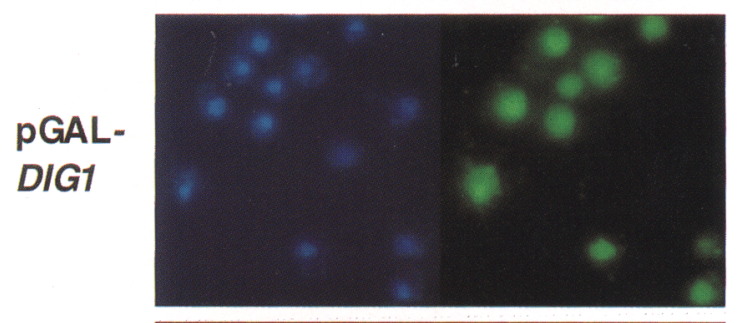

C

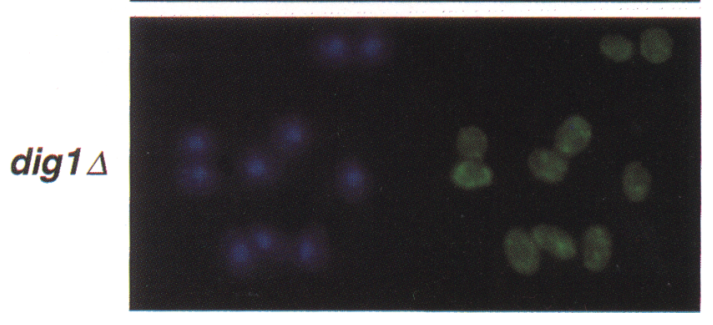

Figure 5. Digl is localized to the nucleus by indirect immunofluorescence. Exponentially growing cultures of YPH499 $(A)$, YPH499 transformed with pGAL1-DIG1 (B), or the dig1D strain, JCY3 $|C|$, were grown in SC medium containing $2 \%$ galactose and $0.2 \%$ sucrose with appropriate nutritional supplements, fixed, permeabilized, and stained with the DNA dye, DAPI lleft column/or with rabbit polyclonal anti-Dig1 antibodies followed by FITC-labeled goat anti-rabbit immunoglobulin (right column|, as described in Materials and Methods.

by the antiserum because only the same diffuse signal was seen when dig1 $\Delta$ cells were examined. As observed previously for Kss1 itself (Ma et al. 1995), localization of Dig1 was unaffected by $\alpha$-factor treatment of $M A T \mathbf{a}$ cells (data not shown). Dig1 was still localized to the nucleus in a kss $1 \Delta$ fus $3 \Delta$ double mutant; hence, nuclear localization of Dig1 does not depend on phosphorylation by, or trafficking in a complex with, either of these MAPKs.

\section{Kss1-Dig1 complexes are detectable in cell extracts}

The interaction between Kss1-GDB and GAD-Digl observed genetically, and the colocalization of native Digl with Kss1 in the nucleus, suggested that Digl and Kss1 have an opportunity to interact physically in the cell. To determine whether Kss1 and Digl associate in vivo, we analyzed whether the two proteins could be coimmunopreciptiated from cell extracts. Toward this end, we expressed in cells either normal Kssl or a version of Kss1 containing at its carboxyl terminus a 10 -residue c-Myc epitope tag (Kss $1-\mathrm{myc})$ that is recognized by the highly specific anti-c-Myc monoclonal antibody (mAb) 9E10 (Evan et al. 1985). To enhance the sensitivity of detec- 
tion, all constructs were expressed at an elevated level from the GAL1 promoter. When extracts of cells cxpressing Kss1-myc were subjected to immunoprecipiation with $\mathrm{mAb} 9 \mathrm{E} 10$, a readily detectable amount of Kss1 was recovered, as determined by immunoblotting with rabbit polyclonal anti-Kss 1 serum (Fig. 6A, left). In contrast, in control cells expressing the untagged Kss1, no Kss1 was immunoprecipitated by $\mathrm{mAb} 9 \mathrm{E} 10$, as expected. When cells expressing Kss 1-myc were also cotransformed with a plasmid expressing DIG1, a readily detectable amount of Digl was found in the Kss 1-myc precipitates (Fig. 6A, right). No Dig1 was immunoprecipitated by $\mathrm{mAb} 9 \mathrm{E} 10$ when DIG1 was coexpressed with the untagged Kss1, confirming that the coimmunoprecipitation observed was a result of an authentic association between Digl and Kss1-myc. Exposure of the cells to pheromone prior to preparation of the lysates only slightly enhanced (if at all) the amount of Digl present in a complex with Kss1myc, in agreement with our finding that pheromone treatment did not affect the interaction between KsslGDB and GAD-Digl, as judged by the two-hybrid method.

\section{Dig1 is a phosphoacceptor substrate for Kss1}

We have demonstrated elsewhere (Bardwell et al. 1996) that the phosphotransferase activity of Kssl toward coimmunoprecipitated and exogenously added substrates can be measured in immune complex kinase assays. For this purpose, the immune complexes obtained as described above, which were bound on bcads (see Materials and Methods|, were incubated in buffer containing $\mathrm{Mg}^{2+}$ and $\left[\gamma^{-32} \mathrm{P}\right] \mathrm{ATP}$, and the resulting radiolabeled species were resolved by SDS-PAGE and examined by autoradiography. To determine whether Dig1 is a substrate for Kss1, Digl was co-overexpressed with c-Myc epitope-tagged versions of wild-type Kssl and a catalytically unactivatable variant, Kssl (T183A Y185F) (Gartner et al. 1992; Ma et al. 1995). A doublet of phosphorylated bands of the appropriate apparent molecular mass to be Digl was observed when Digl was coexpressed with normal Kssl-myc, but only when this MAPK was activated by prior treatment of the cells with pheromone (Fig. 6B, cf. lanes 7 and 8); these species were absent when Digl was coexpressed with the nonactivatable Kssl-myc, whether or not the cells were pretreated with pheromone (Fig. 6B, lanes 9 and 10). Even when DIG1 was expressed at its endogenous level, the phosphorylated Digl species were detectable, albeit faintly, in the immune complexes prepared from cells expressing normal Kssl-myc that had been pheromone-treated (Fig. 6B, cf. lanes 3 and 4 ), but not in cells expressing the unactivatable Kssl-myc mutant before or after pheromone treatment (Fig. 6B, lanes 5 and 6). Thus, the Digl that coimmunoprecipitates with active Kss $1-$ myc is a target substrate for this MAPK.

\section{Kss1 and Dig1 physically associate}

To determine whether the association of Dig1 with Kss1 detected by coimmunopreciptiation from cell extracts represents a direct interaction between these two proteins and does not require any other yeast protein, we
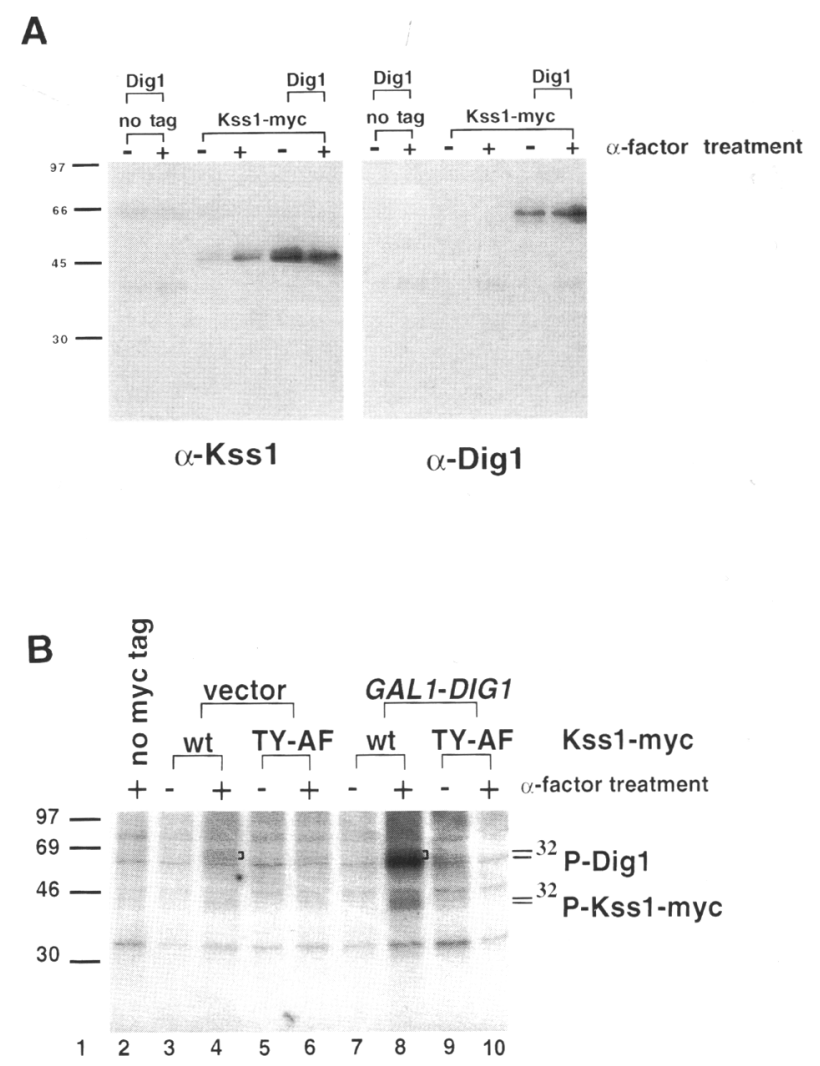

Figure 6. Coimmunoprecipitation of Digl with Kss 1 and phosphorylation of Digl by Kss 1. (A) Protease-deficient strain BJ2168 was transformed with either YEpGAL-KSS1 (no tag) (Ma et al. 1995) or YEpTG-KSS1H6myc (Kss1-myc), along with pGAL1DIG1 (Dig1), where indicated, grown in SC containing $2 \%$ galactose and $0.2 \%$ sucrose with appropriate supplements to maintain selection for the plasmids, treated with $6 \mu \mathrm{M} \alpha$-factor $1+1$ or not $(-\mid$ for $15 \mathrm{~min}$, as indicated, harvested, and lysed, and samples of the resulting extracts were immunoprecipitated with anti-c-Myc mAb 9E10, by procedures described in detail previously (Bardwell et al. 1996). The resulting immune complexes were resolved by SDS-PAGE, transferred to nitrocellulose, and analyzed by immunoblotting with rabbit polyclonal antisera directed against either Kssl (left) or Dig1 (right). (B) Protease-deficient strain BJ2168 was transformed either with YEpGAL-KSS1 (no myc tag) (Ma et al. 1995), with YEpTGKSS1H6myc (wt), or with the nonactivatable mutant YEpTG$K S S 1(A E F) H 6 m y c(T Y-A F)$, along with either a vector alone (YEp352GAL) (Benton et al. 1990) or pGAL1-DIG1, as indicated, grown in SC containing $2 \%$ galactose and $0.2 \%$ sucrose with appropriate supplements to maintain selection for the plasmids, treated with $6 \mu \mathrm{M} \alpha$-factor $(+)$ or not $(-)$ for $15 \mathrm{~min}$, as indicated, harvested, and lysed, and samples of the resulting extracts were immunoprecipitated with anti-c-Myc mAb 9E10, by procedures described in detail previously (Bardwell et al. 1996). The resulting immune complexes were resuspended in protein kinase assay buffer, incubated with $\mathrm{Mg}^{2+}$ and $\left[\gamma^{32} \mathrm{P}\right] \mathrm{ATP}$ for 10 min, and then analyzed by SDS-PAGE and autoradiography, also as described in Bardwell et al. (1996). Doublet representing radiolabeled Digl species indicated by brackets (lanes 4 and 8 ). 
synthesized Kssl by in vitro translation and tested its ability to bind to beads carrying either glutathione $S$-transferase (GST) alone, a GST-Digl(213-452) fusion, or, as a positive control, a GST-Ste7(1-172) fusion (Fig. 7A). We have demonstrated previously that the aminoterminal noncatalytic domain of Ste7 (residues 1-172) binds tightly and specifically to both Kss1 and Fus3 in solution (Bardwell et al. 1996). Kssl was able to bind strongly to both the GST-Dig1(213-452) and the GSTSte7(1-172) fusions, but not to GST alone (Fig. 7A). Thus, the ability of Digl to associate physically with Kssl was demonstrated by four independent criteria: two-hybrid interaction, coimmunoprecipitation, ability to serve as a phosphoacceptor substrate, and direct binding in vitro.

\section{DIG1 and DIG2 encode negative regulators of invasive growth}

Given that the DIG1 gene product is found in the nucleus, associates with Kssl, and can be phosphorylated by Kssl, it was of obvious interest to determine whether Digl plays any role in either of the two signaling pathways in which Kssl functions (mating and invasive growth) by examining the phenotype of Digl-deficient cells. Towards this end, we constructed the dig1$\Delta 1:: H I S 3$ allele in which most of the DIG1 coding sequence is replaced with the HIS3 gene (see Materials and Methods). Given that DIG2 is homologous to DIG1, and also was isolated by virtue of its interaction with Kssl as detected in the two-hybrid screen, we suspected that it might share some partially redundant function with $D I G 1$. Hence, we also constructed the dig2- $\triangle 1:$ TRP1 allele by replacing most of the $D I G 2$ coding sequence with the TRP1 gene (see Materials and Methods). These constructs were used for DNA-mediated transformation of both diploid and haploid recipients of appropriate genotype. We found, first, that neither DIG1 nor DIG2 are essential genes, and that even a dig1 dig2 double mutant shows no overt deficiency in growth rate under a wide variety of conditions. Second, we found that both dig1 and dig2 single mutants, as well as dig1 dig2 double mutants, mated with an efficiency indistinguishable from otherwise isogenic $D I G 1^{+} D I G 2^{+}$cells, and showed a pheromone sensitivity identical to the same controls (data not shown).

Because we could not detect any discernible matingassociated phenotype, we examined whether dig1 and dig2 mutations have any effect on haploid invasive growth. Unlike otherwise isogenic control haploids (and dig1 and dig2 single mutants), the dig1 dig2 double mutant displayed the ability to undergo invasive growth because it was able to penetrate beneath the surface of an agar plate containing rich medium (Fig. 8A). This result was striking because the $\mathrm{S} 288 \mathrm{C}$-derived parental strains (Table 1) in which the dig1 dig2 double mutant was generated have not been reported previously to manifest haploid invasive growth under any condition tested. The dig $1 \Delta$ dig $2 \Delta$ cells remaining in the agar after the wash procedure used to reveal invasive growth were examined
A

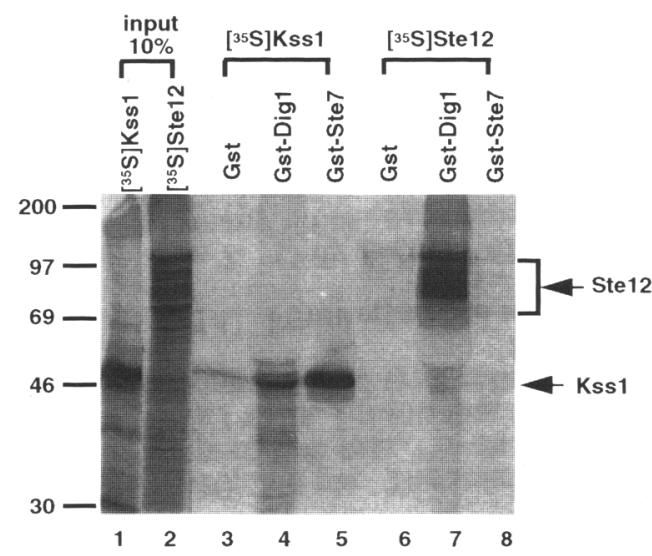

B

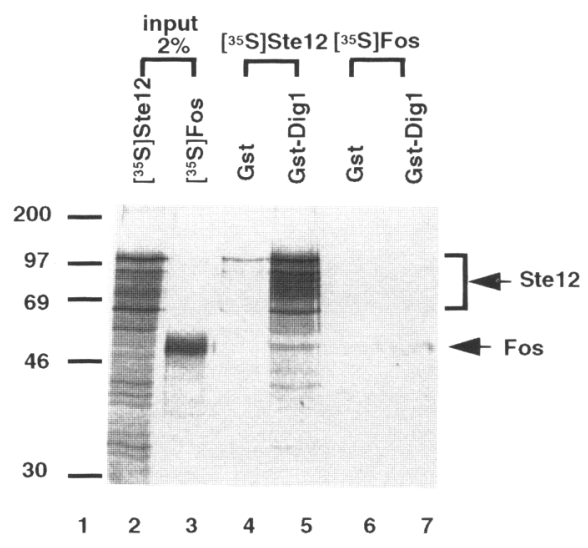

Figure 7. In vitro binding of Kssl and Ste 12 to GST-Digl in vitro. $(A){ }^{35} \mathrm{~S}$-Kssl and ${ }^{35} \mathrm{~S}$-Ste 12 were prepared by in vitro translation, partially purified by ammonium sulfate precipitation, and portions $(10 \%$ of the amount added in the binding reactions, "input") were subjected to SDS-PAGE in a $10 \%$ polyacrylamide gel (lanes 1 and 2$)$. Samples (1 pmole) of the same proteins, each accompanied by $\sim 60 \mu \mathrm{g}$ of total protein from the rabbit reticulocyte lysate, were incubated with approximately equal amounts of bacterially expressed

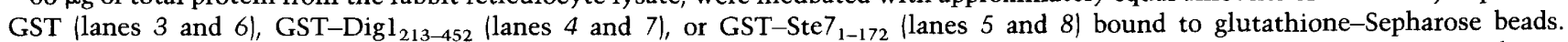
Bead-bound protein complexes were isolated and analyzed on the same gel. Migration positions of molecular mass markers are shown in kilodaltons on the left. The percentage of the input ${ }^{35}$ S-labeled protein bound in the reactions corresponding to lanes 3-8, respectively, was $0.3,4,12,0.6,12$, and $0.5 .(B){ }^{35}$ S-labeled Ste 12 and c-Fos were prepared as described in $A$ and portions $(2 \%$ of the amount added in the binding reactions, "input") were analyzed by SDS-PAGE as in $(A)$ (lanes 2 and 3). Samples (1 pmole) of the same proteins were incubated with $\sim 25$ pmole of purified GST (lanes 4 and 6 ) or GST-Digl $1_{213-452}$ (lanes 5 and 7 ) which had been rebound to glutathione-Sepharose beads, and the resulting bead-bound protein complexes were analyzed in the same gel. Marker proteins of the indicated molecular masses (in kilodaltons) were also resolved on the same gel (lane 1). The percentage of the input ${ }^{35} \mathrm{~S}$-labeled protein bound in the reactions corresponding to lanes $4-7$, respectively, was $0.4,4,0.2$, and 0.3 . 
A

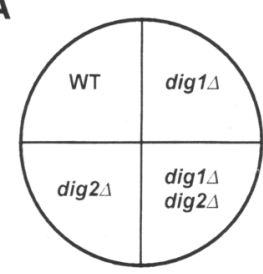

B

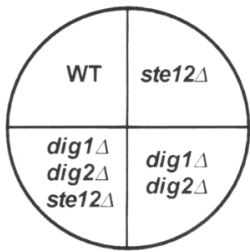

C

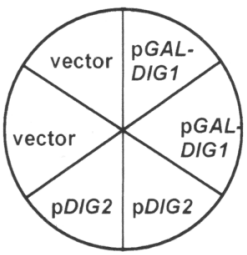

Total Growth
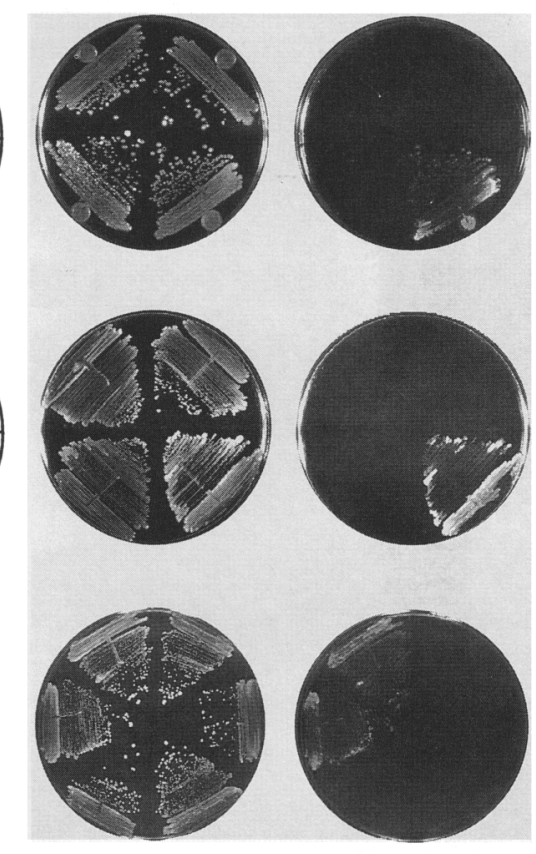

Figure 8. $D I G 1$ and $D I G 2$ are negative regulators of invasive growth. (A) YPH499 (WT) and the otherwise isogenic dig1 $\Delta$ single mutant (JCY3), dig2 $\Delta$ single mutant (JCY4), and dig1 $\Delta$ dig2 $\Delta$ double mutant (JCY5) derivatives, as indicated, were streaked on a rich medium (YPD) plate, incubated for three days at $30^{\circ} \mathrm{C}$ and photographed (left column), and then washed under a water stream to reveal invasive growth and photographed again (right column). (B) A ste12 mutation blocks the invasive growth manifested by a dig1 $1 \Delta$ dig $2 \Delta$ double mutant. YPH499 (WT) and the otherwise isogenic ste12 single mutant (JDY3), dig1s dig2 double mutant (JCY5), and dig1 $\Delta$ dig $2 \Delta$ ste12 $\Delta$ triple mutant (JCY512) derivatives, as indicated, were grown and tested for invasive growth as in $A .(C)$ Expression of either DIG1 or DIG2 rescues the invasive growth manifested by a $\operatorname{dig} 1 \Delta$ dig $2 \Delta$ double mutant. Strain JCY5 (dig1 $\Delta$ dig2 $\Delta$ ) was transformed with a vector (YEp352), plasmid pGAL1-DIG1, or YEp352 carrying the $D I G 2$ gene under the control of its endogenous promoter, grown on plates containing SC-Ura medium with $2 \%$ galactose and $0.2 \%$ sucrose, and examined for invasive growth as in $A$.

under a microscope. In this population, a small proportion $(\sim 1 \%)$ were clearly elongated and in short filamentlike chains (data not shown), as observed during invasive growth by other haploid strains (Roberts and Fink 1994).

It has been shown that the expression of genes required for invasive growth by yeast cells of the $\Sigma 1278$ lineage requires the action of the Ste 12 transcription factor (Liu et al. 1993; Roberts and Fink 1994). To determine whether the invasive growth manifested by the dig1 dig2 double mutant was mediated by the same pathway, we examined the behavior of a dig1 dig2 ste12 triple mutant. The presence of the ste12 mutation completely abolished invasive growth by the dig1 dig2 cells (Fig. 8B), indicating that the loss of Dig1 and Dig2 activates the authentic haploid invasive growth pathway and does not promote invasive growth via some novel

mechanism. Likewise, the invasive growth phenotype displayed by the dig1s dig2 $2 \Delta$ cells was completely reversed by multicopy plasmids expressing either DIG1 (from the GAL1 promoter) or DIG2 (from its endogenous promoter) (Fig. 8C). Thus, Dig1 and Dig2 share a common role in inhibiting invasive growth, at least in the genetic background of certain yeast strains.

\section{Effects of DIG1 overexpression}

The DIG1 gene was also isolated independently in a screen for yeast cDNAs that, when overexpressed, caused haploid cells to appear more resistant to pheromone-imposed $G_{1}$ arrest (S.J. Kron, unpubl.). Indeed, wild-type MATa cells, transformed with a plasmid expressing the DIG1 coding sequence from the inducible GAL1 promoter, formed markedly turbid halos in the standard agar diffusion halo assay for pheromone-induced cell cycle arrest when grown on galactose-containing medium, whereas cells transformed with the empty vector formed larger and completely clear halos (Fig. 9A). Turbid halos are indicative of either increased resistance to pheromone action, or acceleration of the adaptation and recovery process, or both (Reneke et al. 1988). Highlevel expression of DIG1 did not appear to cause turbid halos by inducing expression of SST2 (Dietzel and Kurjan 1987), a gene involved pivotally in the adaptation and recovery process (Dohlman et al. 1996), because DIG1 overexpression caused turbid halos even in an sst2 $\mathrm{Muu}$ $\operatorname{tant}$ (Fig. 9A). In strains lacking either Kss1 (YDM420) or Fus3 (YDM210), overproduction of Dig1 still caused turbid halos (data not shown). Conversely, co-overexpression of either KSS1 or FUS3 from appropriate plasmids (Ma et al. 1995; Bardwell et al. 1996) did not ameliorate the effect of DIG1 overexpression (data not shown), suggesting that it does not block pheromone response by titrating out the MAPKs. Overexpression of DIG2, at least at the level achieved from a multicopy plasmid and driven by its own promoter, which is pheromone-inducible (Fig. 3B), had no detectable effect on halo size or turbidity (data not shown).

Because we demonstrated that both Dig1 and Dig2 act to negatively regulate haploid invasive growth in cells of the S288C background, and because Kss 1 is also required for this process in haploids of the $\Sigma 1278$ lineage (Roberts and Fink 1994), which invade the agar of a rich medium plate quite vigorously, we tested whether overproduction of Dig1 or Dig2 could inhibit invasive growth by $\Sigma 1278$ haploid (Fig. 9B). Overexpression of DIG1 from the GAL1 promoter clearly suppressed invasive growth on a plate containing synthetic complete medium with galactose as the carbon source, whereas cells carrying the empty vector, or cells overexpressing DIG2 (at the level achieved from a multicopy plasmid and driven by its own promoter in the absence of pheromone), did not. Thus, it appears that at least Digl can act as a negative regulator of haploid invasive growth in more than one yeast strain background.

To determine whether Dig1 and Dig2 act as negative regulators of the pseudohyphal growth manifested by 
A
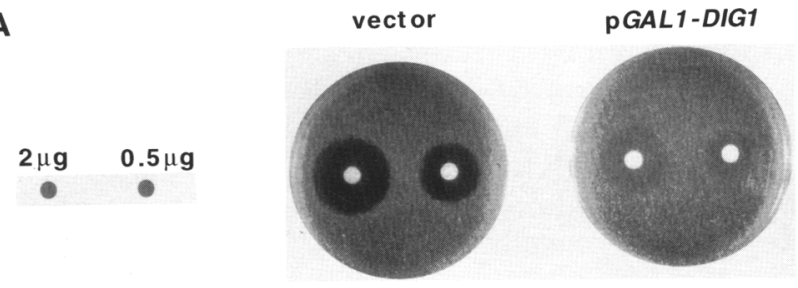

B

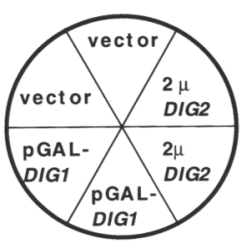

Total Growth

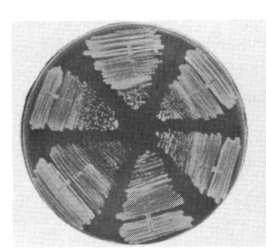

Invasive Growth

C
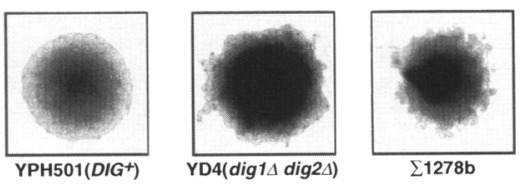

Figure 9. Effect of DIG1 overexpression on pheromone response and invasive growth and effect of DIG1 and DIG2 loss of function on diploid growth. $(A)$ Equivalent amounts $\left(\sim 2 \times 10^{5}\right.$ cells) of exponentially growing cultures of YDM400 transformed with either a vector (YEp352GAL) or pGAL1-DIG1, as indicated, were inoculated in top agar on plates containing SCUra medium with $2 \%$ galactose and $0.2 \%$ sucrose, overlaid with sterile cellulose discs containing either 2 or $0.5 \mu \mathrm{g}$ of synthetic $\alpha$-factor (Peninsula Labs or Star Biochemicals), as indicated, and incubated at $30^{\circ} \mathrm{C}$ for 2 days. (B) A haploid strain of the $\Sigma 1278$ lineage, 10560-4A (see Table 1), was transformed with either a vector control (YEp352GAL), or pGAL1-DIG1, or YEp352$D I G 2$, as indicated, streaked on SC-Ura medium with $2 \%$ galactose and $2 \%$ raffinose, incubated at $30^{\circ} \mathrm{C}$ for two days and then at room temperature for 2 days, photographed (left), rinsed under a gentle stream of distilled water and photographed again (right). (C) Diploid strains YPH501, YD4 and $\Sigma 1278 \mathrm{~b}$ /see Table 1) were grown on synthetic low-ammonia dextrose plates /Gimeno et al. 1992) supplemented with uracil, histidine, adenine, and lysine. Representative colonies were photographed.

diploid cells, we constructed a homozygous dig1/dig1 dig2/dig2 MATa/MAT $\alpha$ diploid in the YPH strain background. We examined the effect of the loss of Digl and Dig2 in this background because YPH strains do not show pseudohyphal growth under any condition tested previously. Unlike the parental strain (YPH501), the colony morphology of the dig1/dig1 dig2/dig2 double mutant diploid displayed elements of filamentous growth that resembled those of the $\Sigma 1278$ diploid strain grown under the same conditions (Fig. 9C), suggesting that Dig1 and Dig2 may also contribute to the negative regulation of pseudohyphal growth in diploids.

\section{Dig1 can physically associate with Ste12}

Our findings raised the possibility that Digl (and Dig2) could negatively regulate haploid invasive growth by act- ing directly on Ste12 to block its action. First, Dig1 was found in the nucleus, like Ste12. Second, overexpression of Dig1 squelched two different Ste12-dependent pathways, invasive growth and mating pheromone response. Third, a ste 12 mutation was epistatic to the constitutive invasive growth displayed by a dig1 dig2 double mutant. To determine whether Ste 12 is capable of binding to Dig1 in vitro, radiolabled Ste 12 was prepared by in vitro translation and tested for its ability to bind to GST alone, to GST-Dig1(213-452), and to GST-Ste7(1-172) (Fig. 7A and B). As additional controls, we tested the ability of another transcriptional transactivator, radiolabeled c-Fos, to associate with these same proteins. Radiolabeled Ste12 was very efficiently bound by the beads carrying GST-Digl(213-452), but was not retained to any significant extent by the beads carrying either GST alone or GST-Ste7(1-172) (Fig. 7A). As expected, c-Fos was not bound by either GST alone or GST-Dig1(213-452) (Fig. 7B). Thus, Ste1 2 can associate specifically with Digl in the absence of any other yeast protein.

\section{Discussion}

We used the two-hybrid screen to isolate two previously unidentified gene products, Dig1 and Dig2, that interact with the MAPK Kssl. We have examined the product of the DIG1 gene in detail because DIG1 is constitutively expressed /unlike the DIG2 gene, which is expressed at a reasonable level only upon pheromone induction). Digl appears to be an authentic substrate of Kssl as judged by several criteria: (1) Both Digl and Kssl are found in the nucleus; (2) Digl associates with Kss1 sufficiently tightly to be coimmunopreciptiated from cell extracts along with this MAPK; (3) Digl is phosphorylated in immune complexes in a Kss1-dependent manner; and (4) Kss 1 can bind tightly to a GST-Digl fusion in vitro. Because Dig2 also was isolated by virtue of its ability to interact with Kssl in vivo, is homologous to Dig1, and shares a common regulatory function with Digl (as judged by genetic analysis|, it seems likely that Dig2 is also a target substrate of Kss1, although this supposition has not been tested directly yet. Because Kss1 is required for haploid invasive growth (Roberts and Fink 1994), and the phenotype of dig1 dig2 double mutants revealed that both proteins are involved in negatively regulating this pathway, it is possible that Kss1-dependent phosphorylation of these proteins is involved in counteracting their inhibitory function, thereby promoting invasive growth. This role for Kss 1 is consistent with the fact that KSS1 is expressed in all three cell types and is not a pheromoneinducible gene (Courchesne et al. 1989).

Because both GAD-Digl and GAD-Dig2 fusions also interacted with a GDB-Fus3 construct in the context of the two-hybrid scheme, it is possible that both proteins are also substrates of Fus3. It has been shown that Fus3 action exerts a negative effect on haploid invasive growth (Roberts and Fink 1994) and that FUS3, like DIG2, is a pheromone-inducible gene (Elion et al. 1990). Hence, phosphorylation by Fus 3 may have some role in enhancing the inhibitory action of Dig2 /and perhaps 
Dig1), and/or in antagonizing the effects of Kss1-mediated phosphorylation of these proteins, to ensure that the invasive growth pathway is fully suppressed when cells are undergoing the mating process. Alternatively, Fus3 association with Digl and Dig2 may simply sterically prevent phosphorylation of these proteins by Kss1.

We favor the model, assumed in the preceding discussion, that: (1) Dig1 and Dig2 are downstream targets of Kss1; (2) they act as negative regulators because they bind to Ste12 and modify its function to prevent the expression of Ste12-dependent genes required for invasive growth (but not those required for mating); and (3) phosphorylation of Dig1 and Dig2 by Kss1 (which presumably becomes activated during nutrient limitation) relieves the inhibitory action of these regulators (Fig. 10). We favor this view for several reasons. First, Digl is a nuclear protein. Second, ste12 mutants do not display invasive growth (Roberst and Fink 1994), and we showed that a ste12 mutation was epistatic to the constitutive invasiveness displayed by dig1 dig2 double mutant.

Nutrient Sufficiency

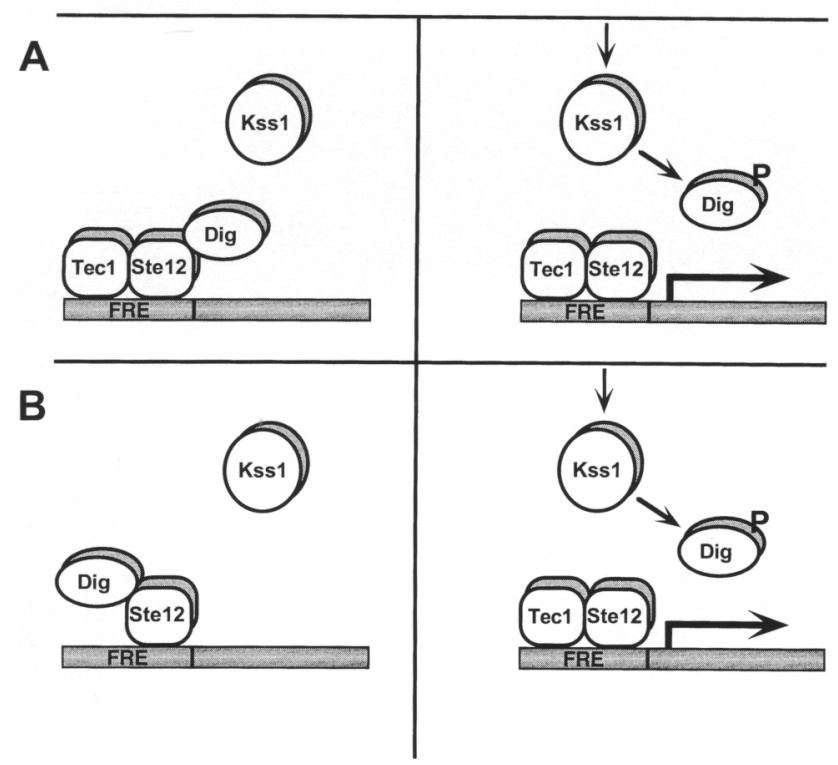

Figure 10. Models for Dig1 and Dig2 action. (A) In the absence of an appropriate signal, Digl (and Dig2) interact with Ste12 bound in a hypothetical complex with Tecl (Gavrias et al. 1996) and prevent activation of promoter elements (filamentous growth response elements, or FREs; H. Madhani and G.R. Fink, in prep.) required for the expression of genes nesessary for invasive growth, but not genes required for mating. Upon an appropriate signal, Kss1 is activated, phosphorylates Digl land Dig2), thereby preventing inhibition of Tec1-Ste12 (and perhaps permitting full phosphorylation of Ste12), allowing expression from FREs. (B) Alternatively, Dig1 (and Dig2) may bind to Ste12 in such a way as to block its ability to associate with Tecl under normal growth conditions. Under conditions of nutrient deprivation, Kss 1-dependent phosphorylation dissociates Digl land Dig2), thereby allowing Tec1 to interact with Ste12, thus promoting gene expression from FREs. See Discussion for further details.
Third, both Dig1 and Ste 12 are phosphorylated by activated Kssl in vitro (L. Bardwell, unpubl.). Fourth, MAPK-dependent phosphorylation has been shown to relieve the inhibitory effect of at least one other negative transcriptional regulator, the Drosophila Yan protein (Rebay and Rubin 1995). Finally, we have found that Ste 12 prepared by in vitro translation can be retained by GST-Dig1 imobilized on beads, but not by GST alone or by another GST fusion protein. Thus, our results provide a critical link between MAPK activation and regulation of the transcriptional events required for induction of the invasive growth pathway.

Because Ste 12 acts at the promoters of genes required for both mating pheromone response and for invasive growth, yet Digl and Dig2 binding to Stel2 affects the action of this transcriptional regulator only at the latter class of promoters, it is likely that this differential effect of Dig1 and Dig2 reflects some intrinsic difference between how Stel 2 acts at these two different classes of promoters (Laloux et al. 1994; Mösch et al. 1996). Indeed, another transcriptional regulator, Tecl (Gavrias et al. 1996), that is required for invasive growth and that acts in cooperation with Ste12 (H. Madhani and G.R. Fink, in prep.), has been described recently. Hence, we favor the view that Dig1 (and Dig2) act either by associating specifically with a presumptive Tecl-Stel 2 complex to block its function (Fig. 10A) or by associating with Ste12 in such a way as to prevent formation of a Tecl-Stel2 complex (Fig. 10B). Thorough characterization of the interactions of all of these proteins will be required to distinguish between these different proposed mechanisms.

Yeast stocks derived from strain S288C, such as the YPH series (Sikorski and Hieter 1989), do not normally manifest either pseudohyphal growth in the diploid state or invasive growth in the haploid state under any laboratory condition. In contrast, strains of the $\Sigma 1278$ pedigree readily form, as diploids, pseudohyphae on medium containing low nitrogen (Gimeno et al. 1992) and, as haploids, invade the agar on plates containing standard rich medium (Roberts and Fink 1994). We have noted that the 乏1278-derived strains invade agar more vigorously than the dig1 dig2 S288C-derived cells on rich medium; however, on synthetic medium, the converse is true (J.G. Cook, unpubl.). The genetic differences between these two strain backgrounds are not fully understood. Mutations in a number of loci, including genes that are also required for the pheromone response pathway, can abolish the ability of the $\Sigma 1278$-derived strains to undergo any dimorphic transition (Liu et al. 1993; Roberts and Fink 1994). Because S288C-derived haploids are matingcomponent, loss of these functions cannot be responsible for their inability to display invasive growth. Conversely, mutations in a wide variety of genes, including those encoding a presumptive protein kinase, ELM1 (Blacketer et al. 1993), a candidate phosphoprotein phosphatase subunit, CDC55 (Healy et al. 1991; Blacketer et al. 1995), and a so-called septin (Chant 1996) or neck filament protein, CDC12 (Blacketer et al. 1995), allow S288C-derived strains to display pseudohyphal growth as diploids and invasive growth as haploids. As we have 
shown here, the list of negative regulators of these developmental processes now includes one demonstrated (Dig1) and one suspected (Dig2) nuclear protein. All cells presumably must express at least the CDC55 and $C D C 12$ genes, because they are essential for viability; so, the loss of these proteins cannot be the reason why a dig1 dig2 double mutant haploid acquires the ability to invade agar.

DIG1 and DIG2 mRNA levels in $\Sigma 1278$ strains appeared similar to those in the YPH strains. It is possible, however, that these transcripts encode inactive forms of the Dig1 and Dig2 proteins, in analogy to the defective $H O$ gene product produced by heterothallic strains of $S$. cerevisiae (Herskowitz et al. 1992). Alternatively, in S288C strains, Digl and Dig2 may be altered such that they are insensitive to the signal that elicits invasive growth, and, thus, S288C-related cells remain incompetent to undergo this transition even under appropriate conditions. However, both of these possibilities seem unlikely because DIG1 overexpression partially suppressed (and DIG2 expression did not prevent) invasive growth in a $\Sigma 1278$ haploid. A more likely scenario, perhaps, is that the mechanism that triggers inactivation of Digl and Dig2 in response to nutrient limitation is defective in S288C strains. For example, in S288C, the Stel1-Ste7-Kss 1 MAPK cascade may be less fully activated in response to nutrient limitation than in $\Sigma 1278$ strains and, thus, unable to overcome the Dig1/Dig2imposed block. In any event, based on the sources of the libraries screened, both the cDNA and genomic sequences described here are from the S288C lineage, which is the DNA sequence determined in the recently completed S. cerevisiae genome project (M. Cherry, pers. comm.)

In the case of filamentous growth by diploids, nitrogen starvation appears to be the signal that induces cells to undergo the transition from the yeast form to the pseudohyphal form (Gimeno et al. 1992). The signal that triggers invasive growth by haploids has not been identified. It seems clear that the decrease in some nutrient and/or the accumulation of some metabolite is responsible for inducing haploids to undergo invasive growth because, initially, a haploid colony grows almost exclusively on the surface of the agar and begins to invade only after several days of incubation, supporting the view that these morphological transitions provide a mechanism whereby an otherwise nonmotile cell can "forage" for more nutrients (Gimeno et al. 1992) (or escape the toxic effect of "pollutants").

Just as signals propagated by the same MAPK cascade allow haploids to mate when stimulated by pheromones or permit cells to undergo invasive growth when induced by the right nutrient conditions, there are other cell types in which activation of the same MAPK pathway elicits quite different cellular responses. For example, the MAPK Erk2 is activated when PC12 cells are treated with epidermal growth factor (EGF), leading to mitogenesis and cellular proliferation, but also when the same cells are treated with nerve growth factor (NGF), leading to a cessation of growth and neuronal differentiation
(Gotoh et al. 1990; Traverse et al. 1992). How different extracellular signals activate the same MAPK cascade, yet are deciphered differently, is not fully understood in any organism, although the duration and extent of MAPK activation may dictate, in part, the nature of the cellular response (Traverse et al. 1994). The available evidence indicates that Dig1 and Dig2 affect developmental decisions at the level of gene regulation /rather than playing a role in preventing the execution of any of the morphological events required for cellular differentiation processes). The unique genetic tractability of $S$. cerevisiae provides a valuable opportunity to investigate how the Dig1 and Dig2 proteins block expression from specific promoters, how that blockade is removed by Kss 1 action, and how these events contribute to the ability of a single MAPK pathway to evoke different developmental outcomes.

\section{Materials and methods}

Strains and growth conditions

Standard yeast media were prepared as described (Sherman et al. 1986), except that, in synthetic minimal medium, twice the recommended level of nutritional supplements was used. Yeast strains used in this work are shown in Table 1. The dig1$\Delta 1:: H I S 3$ allele was constructed in plasmid pGEX-18 (see below) by replacing an internal $0.7-\mathrm{kb} \mathrm{XbaI}-\mathrm{SacI}$ fragment of DIG1 (encoding residues 166-419) with the HIS3 gene extracted from plasmid pJJ215 (Jones and Prakash 1990). This construct was excised as a 2.6-kb EcoRI fragment and used for DNAmediated transformation of a MATa/MAT $\alpha$ strain (YPH501). $\mathrm{His}^{+}$colonies were selected, and disruption of the chromosomal DIG1 locus on one homolog was confirmed by restriction enzyme digestion and hybridization analysis (Southern 1975). The resulting heterozygous diploid was sporulated, and the tetrads so generated were dissected, to yield strain JCY3. The dig2$1 \triangle:: T R P 1$ allele was generated by a method utilizing the polymerase chain reaction (PCR) (Lorenz et al. 1995). For this purpose, the TRP1 gene on plasmid pRS304 (Sikorski and Hieter 1989) was amplified by PCR using primers 103-KO1 (5'-GGTAAGCCTCCTACCATTACGACTTCTCCAGCAGAGAAAACCGTACCCGCAGATTGTACTGAGAGTGC-3' $\mid$ and 103KO2 (5'-CCTTCTTGTCGTTGTCATCATCGGCATCGTCGTTAAGTGAAGCGCCCCTCCTTACGCATCTGTGCGG-3'), each of which possesses homology both to DIG2 (at their $5^{\prime}$ ends) and to the pRS vector series (at their 3 ' ends). The resulting 1.2-kb PCR product (which replaces codons 91-267 of the DIG2 coding sequence with TRP1) was used to transform YPH501 to Trp ${ }^{+}$, and disruption of the chromosomal DIG2 locus on one homolog was confirmed by PCR amplification using primers corresponding to sequences flanking the DIG2 gene and genomic DNA isolated from the transformants or from the parental strain as the template. The resulting heterozygous diploid was sporulated, and the tetrads so generated were dissected, to yield strain JCY4. A dig1 1 dig2 2 double mutant (JCY5) was constructed by transforming strain JCY3 with the dig2$\triangle 1:: T R P 1$ PCR product and confirming the gene replacement by PCR amplification.

\section{Plasmid constructions and recombinant DNA methods}

E. coli strain DH5 $\alpha$ (Hanahan 1983) was used for the propagation of plasmids. A plasmid to express the Kssl-GDB chimera from the constitutive PGK1 promoter (Hitzeman et al. 1980) 
was constructed in several steps. First, codons 1-147 of GAL4 were amplified using primers Gal4-147STOP (5'-CCTTAAGCTTTTACGATACAGTCAACTGTCT-3') and Kss 1-Gal4 joint $\left(5^{\prime}\right.$-|CTAATGAAGACCATGGAAGGGAGCTCTATGA AGCTACTGTCTTCT-3') and a GAL4-containing plasmid pG12 (gift of A. Buchman, Stanford University School of Medicine, Stanford, CA), as the template. The resulting product, which encodes the Gal4 DNA-binding domain followed by a translation termination codon and an SphI site at its $3^{\prime}$ end, and preceded at its $5^{\prime}$ end by nucleotides corresponding to the six most carboxy-terminal codons of KSS1 and a three-amino acid linker (Gly-Ser-Ser) was gel-purified, denatured, and used as the 3' primer in a second round of PCR along with primer Kss 1-3 (5'-GAAATGGTCTCCGGGAAGCCT-3) and, as the template, a DNA fragment containing the $3^{\prime}$ portion of KSS1 that includes an internal $\mathrm{XbaI}$ site. The resulting product was inserted into the EcoRV site in Bluescript KS + (Stratagene) by blunt-end ligation, generating pBS-KCG. pBS-KCG was digested with $\mathrm{Xbal}$ and $S p h I$, and the resulting fragment was used to replace the corresponding XbaI-SphI fragment in YEpGAL-KSS1 (Ma et al. 1995), yielding plasmid pJGCl. pJGCl was digested with $B a m H I$ and SphI and the resulting fragment containing the entire KSS1-GDB fusion was converted to blunt ends by incubation with T4 DNA polymerase in the presence of all four deoxynucleoside triphosphates, and then ligated into a CEN-containing vector, pRS314-PGK (gift of $\mathrm{K}$. Blumer, Washington University, School of Medicine, St. Louis, MO) that had been cleaved with EcoRI and converted to flush ends by the same proceedure. A resulting plasmid containing KSS1-GDB in the correct orientation was identified by restriction endonuclease cleavage site mapping and designated as pJGC2. An otherwise identical construction incorporating a catalytically inactive mutant form of Kss1 was generated by replacing the $1.0-\mathrm{kb}$ $B s i$ WI-BspEI fragment in pICG2 with the corresponding fragment from YEpKSS1(K42R) (Ma et al. 1995).

To express DIG2 from multicopy (2 $\mu \mathrm{m}$ DNA-containing) vectors, first, a $2.2-\mathrm{kb}$ XhoI-Sall fragment containing the entire DIG2 coding sequence and its promoter was excised from a plasmid, pAL138 (gift of Y. Oshima, Osaka University, Osaka, Japan), that carries a large segment of the region of the $S$. cerevisiae genome that surrounds the PHO 8 locus, and inserted into the SalI site of YEp352-HIS3, a derivative of YEp352 (Hill et al. 1986 ) in which HIS3 replaces URA3 (constructed by K. Kuchler, this laboratoryl, yielding YEp352H-DIG2. Second, an EcoRI$S p h I$ fragment carrying the entire DIG2 coding sequence and its promoter was excised from YEpH-DIG2 and ligated into the corresponding sites in YEp352.

Plasmid pGAL-DIG1, originally designated pGAL-Afr 18, was isolated from a library of yeast cDNAs under control of the GAL1 promoter (Liu et al. 1992) by means of a selection for MATa transformants that were able to grow on plates, despite the presence of $\alpha$-factor in the medium (S.J. Kron, unpubl.). To determine the complete nucleotide sequence of the DIG1 coding region, a BamHI-NotI fragment was excised from pGAL$D I G 1$ and inserted into Bluescript $\mathrm{KS}+$. Various internal fragments were subcloned, internal deletions were generated, and the corresponding sequences were determined using primers for T3 and T7 DNA polymerases, as appropriate. Where necessary, custom, synthetic oligonucleotide primers were prepared to obtain overlapping sequences and to resolve any ambiguities. The nucleotide sequence of DIG2 was confirmed in a similar manner.

Multicopy plasmids to express epitope-tagged versions of wild-type Kss1 and a nonactivable variant were constructed in several steps. First, a novel expression vector (YEplac112GAL) was constructed by excising an EcoRI-BamHI fragment con- taining the GAL1 promoter from plasmid pG12 (Nicolet and Friedberg 1987) and inserting it into the corresponding sites of YEplac112 (a TRP1- and 2- $\mu$ m DNA-containing plasmid) (Gietz and Sugino 1988). A BamHI-SphI fragment carrying the entire $K S S 1$ coding sequence was excised from YEpGAL-KSS1 (Ma et al. 1995| and inserted into the corresponding sites of YEplac112GAL, yielding YEpTG-KSS1. A derivative of YEpTG-KSS1 expressing a version of Kss 1 carrying a (His) ${ }_{6}$ tract and a c-Myc-epitope tag (Evan et al. 1985) at its carboxyl terminus was constructed as follows. Oligonucleotide LB52 (5'CCCACCACCACCACCACCACGGTGAACAAAAGTTGATCTCCGAAGAAGACTTGGCTTAAG-3') was annealed to LB53 (5' '-TCGACTTAAGCCAAGTCTTCTTCGGAGATCAACTTTTGTTCACCGTGGTGGTGGTGGTGGTGGGAGCT$3^{\prime}$; partial SalI and SacI sites underlined) to generate a doublestranded oligonucleotide (LB52/53). A BamHI-SacI fragment containing the entire KSS1 coding sequence followed by the Gly-Ser-Ser linker was excised from $\mathrm{pIGCl}$ and ligated, along with LB52/53, into pGEM4Z (Promega Biotech) that had been cut with BamHI and Sall, generating pGEM4Z-KSS1H6myc, which attaches a 21-residue extension (GSSHHHHHHGEQKLISEEDLA-COOH; c-Myc-epitope underlined) to the last residue (position 368) of the authentic Kssl amino acid sequence. A BamHI-SphI fragment containing the KSS1H6myc allele was excised from pGEM4Z-KSS1H6myc and inserted into the corresponding sites of YEplacl12GAL, to yield YEpTGKSS1H6myc. YEpTG-KSS1H6myc was tested for retention of biological function by two independent bioassays. As judged by a patch mating assay (Sprague 1991), the ability of YEpTGKSS1H6myc to complement the sterility of a kss1A fus $3 \Delta$ double mutant strain, YDM230 (Ma et al. 1995), was indistinguishable from that of YEpTG-KSS1. YDM230 carrying either plasmid formed dense patches of diploids under inducing conditions (on galactose medium), mottled patches of diploids under noninducing conditions (on raffinose medium), and no diploids at all under repressing conditions (on dextrose medium). In the standard agar diffusion (halo) assay for pheromone response, high-level expression (on galactose medium) of both YEpTGKSS1 and YEpTG-KSS1H6myc resulted in substantial and indistinguishable inhibition of pheromone-imposed arrest (Courschesne et al. 1989; Ma et al. 1995). Plasmid YEpTG$K S S 1(A E F) \mathrm{H} 6$ myc was constructed by replacing the $0.8-\mathrm{kb}$ BamHI-XbaI fragment in YEpTG-KSS1H6myc with the corresponding fragment from YEpGAL-KSS1(T183A, Y185F) (Ma et al. 1995).

\section{Two-hybrid screen}

Strain Y190 harboring plasmid pJGC2 was transformed with either a library of yeast cDNAs fused to the carboxyl terminus of a construct expressing GAD (generously provided by S. Elledge, Baylor College of Medicine, Houston, TX) or a library of yeast genomic DNA fused to GAD (James et al. 1996) (generously provided by P. James and E.A. Craig, University of Wisconsin, Madison, WI). Fusions capable of interacting with Kss 1 were selected on plates lacking histidine and containing $50 \mathrm{~mm}$ 3-AT (Sigma). The total number of transformants screened was estimated by plating a small fraction of the transformants on medium that selected only for the presence of the test plasmid $\left(\operatorname{Trp}^{+}\right)$and a library plasmid $\left(\mathrm{Leu}^{+}\right)$. Approximately 1.5 million transformants of the cDNA library and about 4.5 million transformants of the genomic DNA library were screened. Positive clones were subjected to a secondary screen for lac $Z$ expression using a nitrocellulose filter replica assay, essentially as described by Breeden and Nasmyth (1985). Extracts were prepared 
from the reproducibly $3-\mathrm{AT}^{\mathrm{R}} \mathrm{LacZ}^{+}$cells and the size of the GAD chimera expressed was examined by SDS-PAGE and immunoblotting using an antiserum raised against the GAD protion (carboxyl terminus) of Gal4 (gift of S. Johnston, University of Texas Southwestern Medical Center, Dallas, TX). Plasmids encoding fusions detectably larger than the GAD domain itself were extracted from the yeast cells and recovered by transformation in E. coli. Specificity for interaction with Kssl was confirmed by failure of the fusions expressed by the recovered library plasmids to give a positive signal when cotransformed with a vector-only control, or with GAD fusions to Raf (Van Aelst et al. 1993) (gift of M. Wigler, Cold Spring Harbor Laboratory, Cold Spring Harbor, NY); Rb (Durfee et al. 1993) (gift of T. Durfee, University of California, Berkeley, CA); Fpr3 (Benton et al. 1994) (gift of N. Dhillon, this laboratory); and Rad3 (Bardwell et al. 1994a). The nucleotide sequences of the inserts in these plasmids were partially determined using primer Gal4850 (5'-GGAATCACTACAGGGATG-3') and compared with the $S$. cerevisiae genome data base using the BLAST-N search algorithm (Altschul et al. 1990).

\section{Analysis of DIG1 and DIG2 mRNAs}

To analyze mRNA levels, total RNA was extracted from cells harvested from exponentially growing cultures $(200 \mathrm{ml})$, essentially as described by Köhrer and Domdey (1991), with the minor modifications that, after precipitation and washing of the crude RNA with ethanol containing $0.01 \%$ diethylpyrocarbonate (DEPC), the resulting pellets were resuspended in $0.5 \mathrm{ml}$ sterile water containing $1 \mu$ l RNAsin solution (Promega) and 1 $\mathrm{mm}$ dithiothreitol, and then adjusted to $0.3 \mathrm{M}$ sodium acetate and $1 \%$ SDS, reprecipitated by addition of two volumes of ethanol containing $0.01 \%$ DEPC (yielding $\sim 250 \mu \mathrm{g} \mathrm{RNA}$ ), and stored at $-80^{\circ} \mathrm{C}$. For pheromone induction, exponentially growing cultures $(50 \mathrm{ml}$ ) of strain DK499 (Table 1) were treated with $0.21 \mu \mathrm{M} \alpha$-factor for $3 \mathrm{hr}$ prior to harvest /after this treatment, virtually every cell was unbudded and had formed a mating projection). To analyze the RNA, samples (50 $\mu \mathrm{g}$ total) were subjected to electrophoresis in a denaturing agarose gel containing $1 \%$ formamide, transferred to a nylon membrane (Boehringer Mannheim), affixed by baking at $80^{\circ} \mathrm{C}$ for $2 \mathrm{hr}$ under vacuum, and annealed with an appropriate radiolabeled DNA probe. ${ }^{32} \mathrm{P}$-labeled probes were prepared by use of the random primer method (Feinberg and Vogelstein 1984) using internal segments of DIG1 (0.7-kb XbaI-SacI fragment) or DIG2 $(0.7-\mathrm{kb}$ EcoRV-Nrul fragment). Hybridization was conducted at $42^{\circ} \mathrm{C}$ overnight and washes were performed at $65^{\circ} \mathrm{C}$ using standard methods (Sambrook et al. 1989). Relative mRNA levels were quantitated using a PhosphorImager (Molecular Dynamics, Inc.) and normalized to the signal observed for the CMD1 transcript (Davis et al. 1986) analyzed in the same fashion.

\section{Preparation of anti-Dig1 antibodies}

To generate a glutathione $S$-transferase (GST)-Digl fusion protein, a 0.8 -kb fragment encoding the 240 most carboxy-terminal residues of Dig1 was excised from the polylinker of one of the DIG1-containing cDNA isolates by digestion with $\mathrm{Bg} / \mathrm{II}$ and inserted into the BamHI site in pGEX-5X (Pharmacia) downstream of and in-frame with the GST coding sequence, yielding pGEX-Digl. Then, to generate a larger fusion, a $1.5-\mathrm{kb}$ fragment containing all but the first six residues of Digl was excised from the polylinker of a different DIG1-containing cDNA isolate by digestion with BglII and inserted into the BamHI site of pGEX$5 \mathrm{X}$, yielding pGEX-18. To prepare antigen, expression of the GST-Dig1 fusion from plasmid pGEX-Dig1 was induced in a protease-deficient $E$. coli strain (BL21) (Studier 1991) by addition of isopropyl- $\beta \mathrm{D}$-thiogalacto-pyranoside (IPTG) to a final concentration of $0.2 \mathrm{~mm}$ followed by incubation with aeration for $2 \mathrm{hr}$ at $30^{\circ} \mathrm{C}$. Cells were harvested, washed once with cold $1 \times$ PBS (Harlow and Lane 1988), and resuspended in 1/20 volume $1 \times$ PBS containing $10 \%$ glycerol and $1 \mathrm{~mm} \mathrm{4-(2-aminoethyl)-}$ benzenesulfonylfluoride (AEBSF). Cells were disrupted by sonication followed by addition of Triton X-100 to a final concentration of $1 \%$. Isoluble material was removed by centrifugation at $12,000 \mathrm{~g}$, and the soluble GST-Digl fusion protein was purified by adsorption to and elution from glutathione-agarose beads (Pharmacia), essentially as directed by the manufacturer, except that elution was performed at $42^{\circ} \mathrm{C}$ in the presence of $1 \%$ Triton X-100 and $0.02 \%$ SDS. The purified protein was used as the immunogen to raise polyclonal antisera in adult female New Zealand White rabbits following standard immunization protocols (Harlow and Lane 1988).

\section{Immunoblotting and immunofluorescence}

For immunoblot analysis, samples (50-100 $\mu \mathrm{g}$ total protein) were subjected to electrophoresis in a $10 \%$ SDS-polyacrylamide gel. Transfer of proteins to nitrocellulose was carried out by use of standard procedures. To detect Kss1, a rabbit polyclonal antiKss I antiserum (Ma et al. 1995) was used at a dilution of 1:5000. To detect Dig1, the rabbit polyclonal antiserum described here was used at dilutions of either 1:2500 or 1:5000. Immobilized immune complexes were detected using a commercial chemiluminescence system (ECL, Amersham) and X-ray film.

Subcellular localization of Digl by indirect immunofluorescence and photomicroscopy was performed by methods described in detail elsewhere (Ma et al. 1995) using the rabbit polyclonal anti-Digl antiserum at dilutions of either 1:300 or $1: 1000$. The secondary antibodies [fluoroscein isothiocyanate [FITC)-conjugated goat antirabbit immunoglobulin] were used at a dilution of $1: 100$.

Coimmunoprecipitation and protein kinase assay in immune complexes

A protease-deficient yeast stain (BJ2168) (Jones 1991) was transformed with either vector alone, YEpGAL-KSS1, YEpTG$K S S 1 \mathrm{H} 6 \mathrm{myc}$, or YEpTG $K S S 1(A E F) \mathrm{H} 6 \mathrm{myc}$, in the presence or absence of pGAL1-DIG1. Cells in the resulting cultures, grown at $30^{\circ} \mathrm{C}$ in appropriate selective medium to mid-exponential phase, were collected by centrifugation, resuspended in fresh prewarmed medium buffered at $\mathrm{pH} 3.5$ with sodium succinate to retard proteolytic degradation of $\alpha$-factor /Ciejek and Thorner 1979), split into two equal portions, incubated with shaking at $30^{\circ} \mathrm{C}$ for $15 \mathrm{~min}$, and then one portion was treated with a final concentration of $6 \mu \mathrm{M} \alpha$-factor and the other was left untreated, followed by incubation for an additional $15 \mathrm{~min}$. Cells were harvested, and extracts were prepared as described in detail in Bardwell et al. (1996). Protein concentration in the resulting extracts was determined by a dye-binding method (Bradford 1976) using commercially available reagents (Bio-Rad) and bovine serum albumin (BSA) as the standard. A volume of extract containing $1 \mathrm{mg}$ of total protein was precleared with a mixture of protein $A$ and protein $G$ conjugated to agarose beads, and then bead-bound immune complexes were prepared using the mAb 9 E10 (Evan et al. 1985) and divided into two equal portions, which were used for immunoblotting and for in vitro protein kinase assays, using methods also described in detail in Bardwell et al. (1996). ${ }^{14} \mathrm{C}$-labeled molecular weight markers were obtained from Amersham.

Bioassays for pheromone response and invasive growth

An agar diffusion (halo) assay was used to measure pheromone- 
induced growth arrest and recovery, as described in detail previously (Reneke et al. 1988). The procedure for revealing invasive growth by washing the surface of agar plates with a stream of water is described in detail elsewhere /Gimeno et al. 1992; Roberts and Fink 1994). To monitor invasive growth by haploid strains, rich medium (YPD) plates (Sherman et al. 1986) were typically used. To examine the effect of DIG1 overexpression on invasive growth by a strain of the $\Sigma 1278$ lineage, SC-Ura medium (to maintain selection for the DIG1-containing plasmid) containing $2 \%$ galactose and $2 \%$ raffinose (to induce expression of DIG1 from the GAL1 promoter) was used, plates were incubated for three days, and were photographed immediately after washing.

\section{In vitro protein interaction assays using GST fusions}

For in vitro binding assays, GST fusion proteins were expressed in E. coli and bound to glutathione-agarose beads, as instructed by the manufacturer. Equal amounts of protein-coated beads were further incubated with 1 pmole of radiolabeled proteins, prepared by in vitro translation as described (Bardwell et al. 1996). Incubations were carried out at room temperature for $1 \mathrm{hr}$ in $0.2 \mathrm{ml}$ Buffer A (Bardwell et al. 1996) followed by two 1-ml washes with ice cold Buffer A. Bound proteins were eluted in SDS-PAGE sample buffer containing 5\% SDS and $60 \mathrm{~mm}$ dithiothreitol (DTT). One half of each sample was loaded on a $10 \%$ polyacrylamide gel along with samples of the input in vitro translated proteins as markers. Alternatively, equal amounts of purified GST fusion proteins that had been eluted in $20 \mathrm{~mm}$ glutathione were diluted to $0.5 \mathrm{~mm}$ glutathione in Buffer $\mathrm{A}$ and rebound to glutathione-agarose beads at room temperature for 1 hr. The beads were collected and washed twice with ice-cold Buffer A prior to incubation with the radiolabeled proteins, as above.

\section{Acknowledgments}

We thank Gustav Ammerer, Andy Buchman, Tim Durfee, Stan Fields, Stephen Johnston, Yasuji Oshima, George F. Sprague, Jr., and Michael Wigler for the generous gift of reagents. S.J.K. especially thanks Gerald R. Fink for his generous support. We are also indebted to Steve Elledge for providing the two-hybrid reporter strain and the yeast cDNA library, and to Phil James and Betty Craig for supplying the yeast genomic DNA library. We are very grateful to members of our laboratory, especially Carla Inouye, Jennifer Davis, Namrita Dhillon, David Kaim, Doreen $\mathrm{Ma}$, and Elana Swartzman, who supplied plasmids, strains, technical assistance, and advice, as well as helpful discussions and insightful comments. We thank Randy Schekman for the use of his PhosphorImager.

This work was supported by National Institutes of Health (NIH) Predoctoral Traineeship GM07232 and an Academic Development Program predoctoral fellowship from Merck \& Co., Inc. (to J.G.C.), by NIH-National Research Service Award Postdoctoral Fellowship GM15871 (to L.B.), by a postdoctoral fellowship from the Helen Hay Whitney Foundation (to S.J.K.), by NIH Research Grant GM21841 (to J.T.), and by facilities provided by the Berkeley campus Cancer Research Laboratory.

The publication costs of this article were defrayed in part by payment of page charges. This article must therefore be hereby marked "advertisement" in accordance with 18 USC section 1734 solely to indicate this fact.

\section{References}

Altschul, S.F., W. Gish, W. Miller, E.W. Myers, and D.J. Lipman. 1990. Basic local alignment search tool. I. Mol. Biol. 215: 403-410.
Alvarez, E., I.C. Northwood, F.A. Gonzales, D.A. Latour, A. Seth, C. Abate, T. Curran, and R.J. Davis. 1991. Pro-Leu-Ser/ Thr-Pro is a consensus primary sequence for substrate protein phosphorylation. Characterization of the phosphorylation of c-myc and c-jun proteins by an epidermal growth factor receptor threonine 669 protein kinase. J. Biol. Chem. 266: 15277-15285.

Bardwell, L., A.J. Bardwell, W.J. Feaver, J.Q. Svejstrup, R.D. Kornberg, and E.C. Friedberg. 1994a. Yeast RAD3 protein binds directly to both SSL2 and SSL1 proteins: Implications for the structure and function of transcription/repair factor b. Proc. Natl. Acad. Sci. 91: 3926-3930.

Bardwell, L., J.G. Cook, C.J. Inouye, and J. Thorner. 1994b. Signal propagation and regulation in the mating pheromone response pathway of the yeast Saccharomyces cerevisiae. Dev. Biol. 166: 363-379.

Bardwell, L., J.G. Cook, E.C. Chang, B. Cairnes, and J. Thorner. 1996. Signaling in the yeast pheromone response pathway: Specific and high-affinity interaction of the mitogen-activated protein (MAP) kinases Kss1 and Fus3 with the upstream MAP kinase kinase Ste7. Mol. Cell. Biol. 16: 36373650.

Bartel, P.L. and S. Fields. 1995. Analyzing protein-protein interactions using the two-hybrid system. Methods Enzymol. 254: 241-263.

Benton, B.M., W.K. Eng, J.J. Dunn, F.W. Studier, R. Sternglanz, and P.A. Fisher. 1990. Signal-mediated import of bacteriophage T7 RNA polymerase into the Saccharomyces cerevisiae nucleus and specific transcription of target genes. Mol. Cell. Biol. 10: 353-360.

Benton, B.M., J.-H. Zang, and J. Thorner. 1994. A novel FK506and rapamycin-binding protein (FPR3 gene product) in the yeast Saccharomyces cerevisiae is a proline rotamase localized to the nucleolus. J. Cell. Biol. 127: 623-639.

Blacketer, M.J., C.M. Koehler, S.G. Coats, A.M. Myers, and P. Madaule. 1993. Regulation of dimorphism in Saccharomyces cerevisiae: Involvement of the novel protein kinase homolog Elmlp and protein phosphatase 2A. Mol. Cell. Biol. 13: $5567-5581$.

Blacketer, M.J., P. Madaule, and A.M. Myers. 1995. Mutational analysis of morphologic differentiation in Saccharomyces cerevisiae. Genetics 140: 1259-1275.

Boeke, J.D., F. LaCroute, and G.R. Fink. 1984. A positive selection for mutants lacking orotidine 5-phosphate decarboxylase activity in yeast: $5^{\prime}$-fluoro-orotic acid resistance. Mol. Gen. Genet. 197: 345-346.

Bradford, M.M. 1976. A rapid and sensitive method for the quantitation of microgram quantities of protein utilizing the principle of protein-dye binding. Anal. Biochem. 72: 248254.

Breeden, L. and K. Nasmyth. 1985. Regulation of the yeast HO gene. Cold Spring Harbor Symp. Quant. Biol. 50: 643-650.

Cairns, B.R., S.W. Ramer, and R.D Kornberg. 1992. Order of action of components in the yeast pheromone response pathway revealed with a dominant allele of the STE11 kinase and the multiple phosphorylation of the STE7 kinase. Genes \& Dev. 6: 1305-1318.

Chan, R.K., L.M. Melnick, L.C. Blair, and J. Thorner. 1983. Extracellular suppression allows mating by pheromone-deficient sterile mutants of Saccharomyces cerevisiae. J. Bacteriol. 155: 903-906.

Chang, F. and I. Herskowitz. 1990. Identification of a gene necessary for cell cycle arrest by a negative growth factor of yeast: FAR1 is an inhibitor of a G1 cyclin, CLN2. Cell 63: 999-1011.

_ 1992 . Phosphorylation of FAR1 in response to alpha- 
factor: A possible requirement for cell-cycle arrest. Mol. Cell. Biol. 4: 445-450.

Chant, J. 1996. Septin scaffolds and cleavage planes in Saccharomyces. Cell 84: 187-190.

Choi, K.Y., B. Satterberg, D.M. Lyons, and E.A. Elion. 1994. Ste5 tethers mutiple protein kinases in the MAP kinase cascade required for mating in S. cerevisiae. Cell 78: 499-512.

Ciejek, E.M. and J. Thorner. 1979. Recovery of S. cerevisiae a cells from Gl arrest by alpha-factor requires endopeptidase action. Cell 18: 623-635.

Clark-Lewis, I., J.S. Sanghera, and S.L. Pelech. 1991. Definition of a consensus sequence for peptide substrate recognition by p44mpk, the meiosis-activated myelin basic protein kinase. J. Biol. Chem. 266: 15180-15184.

Courchesne, W.E., R. Kunisawa, and J. Thorner. 1989. A putative protein kinase overcomes pheromone-induced arrest of cell cycling in S. cerevisae. Cell 58: 1107-1119.

Davis, R.J. 1993. The mitogen-activated protein kinase signal transduction pathway. J. Biol. Chem. 268: 14553-14556.

Davis, T.N., M.S. Urdea, F.R. Masiarz, and J. Thorner. 1986. Isolation of the yeast calmodulin gene: Calmodulin is an essential protein. Cell 47: 423-431.

Dhanasekaran, N., L.E. Heasley, and G.L. Johnson. 1995. G protein-coupled receptor systems involved in cell growth and onocogenesis. Endocr. Rev. 16: 259-270.

Dietzel, C. and J. Kurjan. 1987. Pheromonal regulation and sequence of the Saccharomyes cerevisiae SST2 gene: A model for desensitization to pheromone. Mol. Cell. Biol. 7: 41694177.

Dohlman, H.G., J. Song, D. Ma, W.E. Courchesne, and J. Thorner. 1996. Sst, a negative regulator of pheromone signaling in the yeast Saccharomyces cerevisiae: Expression, localization, genetic interaction and physical association with Gpal (G protein $\alpha$ subunit). Mol. Cell. Biol. 16: 5194 5209.

Dolan, J.W., D. Kirkman, and S. Fields. 1989. The yeast STE12 protein binds to the DNA sequence mediating pheromone induction. Proc. Natl. Acad. Sci. 86: 5703-5707.

Durfee, T., K. Becherer, P. Chen, S. Yeh, Y. Yang, A.E. Kilburn, W. Lee, and S.J. Elledge. 1993. The retinoblastoma protein associates with the protein phosphatase type 1 catalytic subunit. Genes \& Dev. 7: 555-569.

Elion, E., P. Grisafi, and G. Fink. 1990. FUS3 encodes a cdc2 +/ CDC28-related kinase required for the transition from mitosis into conjugation. Cell 60: 649-644.

Elion, E., J. Brill, and G. Fink. 1991. FUS3 represses CLN1 and CLN2 and in concert with KSS1 promotes signal transduction. Proc. Natl. Acad. Sci. 88: 9392-9396.

Elion, E.A., B. Satterberg, and J.E. Kranz. 1993. FUS3 phosphorylates multiple components of the mating signal transduction cascade: Evidence for STE12 and FAR1. Mol. Biol. Cell 4: 495-510.

Errede, B. and Q.-Y. Ge. 1996. Feedback regulation of MAP kinase signal pathways. Philos. Trans. R. Soc. Lond. B. Biol. Sci. 351: 143-148.

Errede, B., A. Gartner, Z. Zhou, K. Masmyth, and G. Ammerer. 1993. MAP kinase-related Fus3 from $S$. cerevisiae is activated by Ste7 in vitro. Nature 362: 261-264.

Evan, G.I., G.K. Lewis, G. Ramsay, and J.M. Bishop. 1985. Isolation of monoclonal antibodies specific for human c-myc proto-oncogene product. Mol. Cell. Biol. 5: 3610-3616.

Feinberg, A.P. and B. Vogelstein. 1984. A technique for radiolabeling DNA restriction endonuclease fragments to high specific activity. Anal. Biochem. 137: 266-267.

Fields, S. and O. Song. 1989. A novel genetic system to detect protein-protein interactions. Nature 340: 245-246.
Gartner, A., K. Nasmyth, and G. Ammerer. 1992. Signal transduction in Saccharomyces cerevisiae requires tyrosine and threonine phosphorylation \% of FUS3 and KSS1. Genes \& Dev. 6: 1280-1292.

Gavrias, V., A. Andrianopoulos, C.J. Gimeno, and W.E. Timberlake. 1996. Saccharomyces cerevisiae TEC1 is required for pseudohyphal growth. Mol. Microbiol. 19: 1255-1263.

Gietz, R.D. and A. Sugino. 1988. New yeast-Escherichia coli shuttle vectors constructed with in vitro mutagenized yeast genes lacking six-base-pair restriction sites. Gene 74: 527534.

Gimeno, C.J., P.O. Ljungdahl, C.A. Styles, and G.R. Fink. 1992. Unipolar cell divisions in the yeast $S$. cerevisiae lead to filamentous growth: Regulation by starvation and RAS. Cell 68: 1077-1090.

Gotoh, Y., E. Nishida, T. Yamashita, M. Hoshi, M. Kawakami, and H. Sakai. 1990. Microtubule-associated-protein (MAP) kinase activated by nerve growth factor and epidermal growth factor in PC12 cells. Identity with the mitogen-activated MAP kinase of fibroblastic cells. Eur. J. Biochem. 193: 661-669.

Hanahan, D. 1983. Studies on transformation of Escherichia coli with plasmids. I. Mol. Bio. 166: 557-580.

Harlow, E. and D. Lane. 1988. Antibodies: A laboratory manual. Cold Spring Harbor Laboratory, Cold Spring Harbor, NY.

Healy, A.M., S. Zolnierowicz, A.E. Stapleton, M. Goebl, A.A. DePaoli-Roach, and J.R. Pringle. 1991. CDC55, a Saccharomyces cerevisiae gene involved in cellular morphogenesis: Identification, characterization, and homology to the B subunit of mammalian type $2 \mathrm{~A}$ protein phosphatase. Mol. Cell. Biol. 11: 5767-5780.

Herskowitz, I. and R.E. Jensen. 1991. Putting the HO gene to work: Practical uses for mating-type switching. Methods Enzymol. 194: 132-146.

Herskowitz, I., J. Rine, and J. Strthern. 1992. Mating-type determination and mating-type interconversion in Saccharomyces cerevisiae. In The molecular and cellular biology of the yeast Saccharomyces: Gene expression (ed. E.W. Jones, J.R. Pringle, and J.R. Broach), pp. 583-656. Cold Spring Harbor Laboratory Press, Cold Spring Harbor, NY.

Hill, J.E., A.M. Myers, T.J. Koerner, and A. Tzagoloff. 1986. Yeast/E. coli shuttle vectors with multiple unique restriction sites. Yeast 2: 163-167.

Hitzeman, R.A., L. Clarke, and J. Carbon. 1980. Isolation and characterization of the yeast 3-phosphoglycerokinase gene (PGK1) by an immunological screening technique. I. Biol. Chem. 255: 12073-12080.

James, P., J. Halladay, and E.A. Craig. 1996. Genomic libraries and a host strain designed for highly efficient two-hybrid selection in yeast. Genetics (in press).

Jones, E.W. 1991. Tackling the protease problem in yeast. Methods Enymol. 194: 428-453.

Jones, J.S. and L. Prakash. 1990. Yeast Saccharomyces cerevisiae selectable markers in pUC18 polylinkers. Yeast 6: 363366.

Julius, D., L. Blair, A. Brake, G. Sprague, and J. Thorner. 1983. Yeast alpha factor is processed from a larger precursor polypeptide: The essential role of a membrane-bound dipeptidyl aminopeptidase. Cell 32: 839-852.

Klopotowski, T. and A. Wiater. 1965. Synergism of aminotriazole and phosphate on the inhibition of yeast imidazoleglycerolphosphate dehydratase. Arch. Biochem. Biophys. 112: $562-566$.

Köhrer, K. and H. Domdey. 1991. Preparation of high molecular weight RNA. Methods Enzymol. 194: 398-405. 
Kranz, J.E., B. Satterberg, and E.A. Elion. 1994. The MAP kinase Fus3 associates with and phosphorylates the upstream signaling component Ste5. Genes \& Dev. 8: 313-327.

Kron, S.J. and N.A.R. Gow. 1995. Budding yeast morphogenesis-Signaling, cytoskeleton, and cell cycle. Curr. Opin. Cell Biol. 7: 845-855.

Kron, S.J., C.A. Styles, and G.R. Fink. 1994. Symmetric cell division in pseudohyphae of the yeast Saccharomyces cerevisiae. Mol. Biol. Cell 51: 003-1022.

Kurjan, J. 1993. The pheromone response pathway in Saccharomyces cerevisiae. Annu. Rev. Genet. 27: 147-179.

Laloux, I., E. Jacobs, and E. Dubois. 1994. Involvement of SRE element of Tyl transposon in TEC1-dependent transcriptional activation. Nucleic Acids Res. 22: 999-1005.

Leberer, E., D. Dignard, D. Harcus, D.Y. Thomas, and M. Whiteway. 1992. The protein kinase homolog Ste20p is required to link the yeast pheromone response G-protein $\beta \gamma$ subunits to downstream signalling components. EMBO /. 11:48154824.

Leeuw, T., A. Fourest-Lieuvin, C. Wu, J. Chenevert, K. Clark, M. Whiteway, D.Y. Thomas, and E. Leberer. 1995. Pheromone response in yeast: Association of Bemlp with proteins of the MAP kinase cascade and actin. Science 270: 1210 1213.

Lipman, D.J. and W.R. Pearson. 1985. Rapid and sensitive protein similarity searches. Science 227: 1435-1441.

Liu, H., J. Krizek, and A. Bretscher. 1992. Construction of a Gal1-regulated yeast cDNA expression library and its application to the identification of genes whose overexpression causes lethality in yeast. Genetics 132: 665-673.

Liu, H., C. Styles, and G.R. Fink. 1993. Elements of the yeast pheromone response pathway required for filamentous growth of diploids. Science 262: 1741-1744.

Lorenz, M.C., R.S. Muir, E. Lim, J. McElver, S.C. Weber, and J. Heitmen. 1995. Gene disruption with PCR products in Saccharomyces cerevisiae. Gene 158: 113-117.

Ma, D., J.G. Cook, and J. Thorner. 1995. Phosphorylation and localization of Kss1, a MAP kinase of the Saccharomyces cerevisiae pheromone response pathway. Mol. Biol. Cell 6: 889-909.

Manser, E., T. Leung, H. Salihuddin, Z.S. Zhao, and L.Lim. 1994. A brain serine/threonine protein kinase activated by Cdc42 and Racl. Nature 367: 40-46.

Marcus, S., A. Polverino, M. Barr, and M. Wigler. 1994. Complexes between STE5 and components of the pheromoneresponsive mitogen-activated protein kinase module. Proc. Natl. Acad. Sci. 91: 7762-7766.

Martin, G.A., G. Bollag, F. McCormick, and A. Abo. 1995. A novel serine kinase activated by rac1/CDC42Hs-dependent autophosphorylation is related to PAK65 and STE20. EMBO J. 14: $1970-1978$.

Miller, J.H. 1972. Experiments in molecular genetics. Cold Spring Harbor Laboratory, Cold Spring Harbor, NY.

Mösch, H.-U., R.L. Roberts, and G.R. Fink. 1996. Ras2 signals via the $\mathrm{Cdc} 42 /$ Ste20/mitogen-activated protein kinase module to induce filamentous growth in Saccharomyces cerevisiae. Proc. Natl. Acad. Sci. 93: 5352-5356.

Nieman, A.M. and I. Herskowitz. 1994. Reconstitution of a yeast protein kinase cascade in vitro: Activation of the yeast MEK homologue STE7 by STE11. Proc. Natl. Acad. Sci. 91: 3398-3402.

Nicolet, C. and E. Friedberg. 1987. Overexpression of the RAD2 gene of $S$. cerevisiae: Identification and prelimiary characterization of Rad2 protein. Yeast 3: 149-160.

Osborne, M.A. and P.A. Silver. 1993. Nucleocytoplasmic transport in the yeast Saccharomyces cerevisiae. Annu. Rev. Bio- chem 62: 219-254.

Peter, M., A. Gartner, J. Horecka, G. Ammerer, and I. Hershowitz. 1993. FAR l links the signal transduction pathway to the cell cycle machinery in yeast. Cell 73: 747-760.

Printen, J.A. and G.F. Sprague, Jr. 1994. Protein-protein interactions in the yeast pheromone response pathway: Ste5P interacts with all members of the MAP kinase cascade. Genetics 138: 609-619.

Rebay, I. and G.M. Rubin. 1995. Yan functions as a general inhibitor of differentiation and is negatively regulated by activation of the Ras1/MAPK pathway. Cell 81: 857-866.

Reneke, J.E., K.J. Blumer, W.E. Courshesne, and J. Thorner. 1988. The carboxy-terminal segment of the yeast alpha-factor receptor is a regulatory domain. Cell 55: 221-234.

Roberts, R.L. and G.R. Fink. 1994. Elements of a single MAP kinase cascade in Saccharomyces cerevisiae mediate two developmental programs in the same cell type: Mating and invasive growth. Genes \& Dev. 8: 2974-2985.

Sambrook, J., E. Fritsch, and T. Maniatis. 1989. Molecular cloning: A laboratory manual, 2nd edition. Cold Spring Harbor Laboratory Press, Cold Spring Harbor, NY.

Scherer, S. and R.W. Davis. 1979. Replacement of chromosomal segments with altered DNA sequences constructed in vitro. Proc. Natl. Acad. Sci. 76: 4951-4955.

Sherman, F., G.R. Fink, and J.B. Hicks. 1986. Laboratory course manual for methods in yeast genetics. Cold Spring Harbor Laboratory, Cold Spring Harbor, NY.

Sikorski, R.S. and P. Hieter. 1989. A system of shuttle vectors and yeast host strains designed for efficient manipulation of DNA in Saccharomyces cerevisiae. Genetics 122: 19-27.

Simon, M.N., C. De Virgilio, B. Souza, J.R. Pringle, A. Abo, and S.I. Reed. 1995. Role for the Rho-family GTPase Cdc42 in yeast mating-pheromone signal pathway. Nature 376: 702705.

Southern, E.M. 1975. Detection of specific sequences among DNA fragments separated by gel electrophoresis. I. Mol. Biol. 98: 503-517.

Spraguc, G.F., Jr. 1991. Assay of the yeast mating reaction. Methods Enzymol. 194: 77-93.

Sprague, G.F., Jr. and J. Thorner. 1992. Pheromone response and signal transduction during the mating process of Saccharomyces cerevisiae. In The molecular and cellular biology of the yeast Saccharomyces: Gene expression (ed. E.W. Jones, J.R. Pringle, and J.R. Broach), pp. 657-744. Cold Spring Harbor Laboratory Press, Cold Spring Harbor, NY.

Studier, F.W. 1991. Use of bacteriophage T7 lysozyme to improve an inducible $\mathrm{T} 7$ expression system. I. Mol. Biol. 219: $37-44$.

Traverse, S., N. Gomez, H. Paterson, C. Marshall, and P. Cohen. 1992. Sustained activation of the mitogen-activated protein (MAP) kinase cascade may be required for differentiation of $\mathrm{PCl} 2$ cells. Comparison of the effects of nerve growth factor and epidermal growth factor. Biochem. I. 288: 351-355.

Traverse, S., K. Seedorf, H. Paterson, C.J. Marshall, P. Cohen, and A. Ullrich. 1994. EGF triggers neuronal differentiation of PCl2 cells that overexpress the EGF receptor. Curr. Biol. 4: 694-701.

Tyers, M. and B. Futcher. 1993. Farl and Fus3 link the mating pheromone signal transduction pathway to three Gl-phase Cdc28 kinase complexes. Mol. Cell. Biol 13: 5659-5669.

Van Aelst, L., M. Barr, S. Marcus, A. Polverino, and M. Wigler. 1993. Complex formation between RAS and RAF and other protein kinases. Proc. Natl. Acad. Sci. 90: 6213-6217.

Van Arsdell, S.W. and J. Thorner. 1987. Hormonal regulation of gene expression in yeast. In Transcriptional control mecha nisms (ed. D.K. Granner, M.G. Rosenfeld, and S. Chang), pp. 
Cook et al.

325-332. Alan R. Liss, New York, NY.

Whiteway, M., L. Hougan, D. Dignard, D.Y. Thomas, L. Bell, G.C. Saari, F.J. Grant, P. O'Hara, and V.L. MacKay. 1989. The STE4 and STE18 genes of yeast encode potential $\beta$ and gamma subunits of the mating factor receptor-coupled $G$ protein. Cell 56: $467-477$.

Wiame, J.M., M. Grenson, and H.M. Arst, Jr. 1985. Nitrogen catabolite repression in yeasts and filamentous fungi. $A d v$. Microbiol. Physiol. 26: 1-88.

Wu, C., M. Whiteway, D.Y. Thomas, and E. Leberer. 1995. Molecular characterization of Ste20p, a potential mitogen-activated protein or extracellular signal-regulated kinase kinase (MEK) kinase kinase from Saccharomyces cerevisiae. J. Biol. Chem. 270: 15984-15992.

Zhao, Z.S., T. Leung, E. Manser, and L. Lim. 1995. Pheromone signalling in Saccharomyces cerevisiae requires the small GTP-binding protein Cdc42p and its activator Cdc24. Mol. Cell. Biol. 15: 5246-5257. 


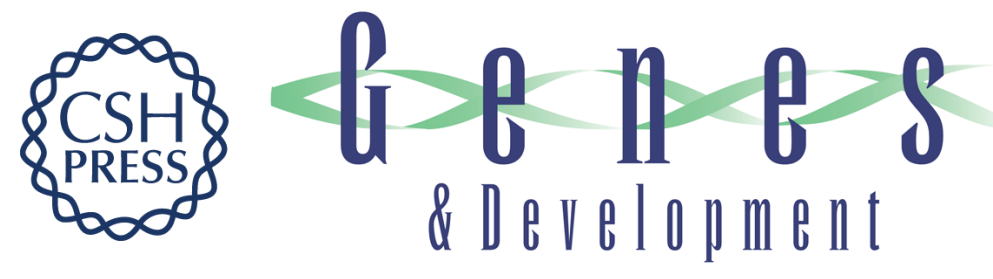

\section{Two novel targets of the MAP kinase Kss1 are negative regulators of invasive growth in the yeast Saccharomyces cerevisiae.}

J G Cook, L Bardwell, S J Kron, et al.

Genes Dev. 1996, 10:

Access the most recent version at doi:10.1101/gad.10.22.2831

References This article cites 90 articles, 40 of which can be accessed free at:

http://genesdev.cshlp.org/content/10/22/2831.full.html\#ref-list-1

License

Email Alerting

Service

Receive free email alerts when new articles cite this article - sign up in the box at the top right corner of the article or click here.

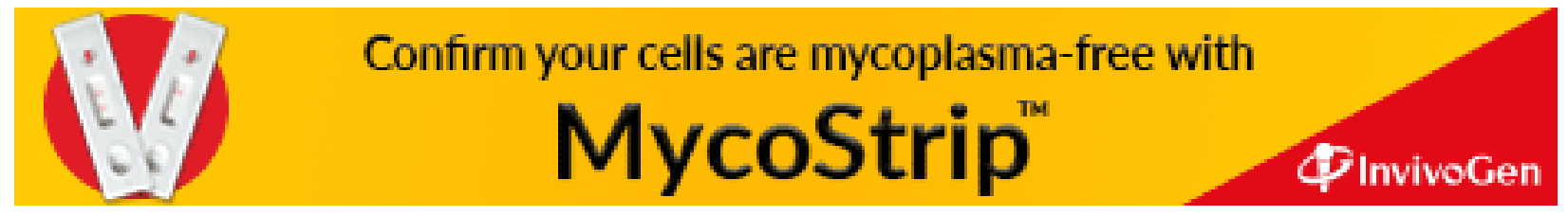

